\title{
Associations between dental caries and systemic diseases: a scoping review
}

\author{
Amarpreet Sabharwal ${ }^{1,2^{*}} \mathbb{D}$, Elizabeth Stellrecht ${ }^{3}$ and Frank A. Scannapieco ${ }^{4}$
}

\begin{abstract}
Background: The objective of this study was to evaluate and present evidence from animal and human clinical studies on associations between dental caries and systemic diseases, and to suggest potential mechanisms that might explain such associations.

Methods: An electronic search was conducted of PubMed, Embase and Cochrane Central Register of Controlled Trials for articles published from 2010 to 2020 in the English language. From the initial search, 404 full-text studies were assessed for eligibility. After excluding studies for technical and study limitations, a total of 67 studies were included in the summary tables and additional studies were included in the review to support evidence.
\end{abstract}

Results: Few systemic disease and conditions were found to be clinically meaningfully associated with caries experience. Best evidence from human and animal studies described association between metabolic diseases and dental caries. Several interesting animal studies were noted that could generate clinical hypotheses and further investigations in rodent models for cardiovascular injury and hyperglycemia. Inadequate data was found to suggest any modifications to current clinical practice or prevention guidelines.

Conclusions: Limited clinical evidence was found connecting several systemic diseases and dental caries. Inadequate data was found to suggest any modifications to current clinical practice or prevention guidelines.

Clinical significance: Understanding of associations between dental caries and systemic diseases play a crucial role in the treatment planning and education of the dental patient.

Keywords: Dental caries, Oral health, Risk factors, Inflammation, Diabetes mellitus, Type 2, Microbiota

\section{Background}

Dental caries is one of the most prevalent conditions worldwide [1] and accounts for significant morbidity [2]. Importantly, the prevalence of untreated dental caries has increased $[1,2]$. While there is a direct effect of untreated dental caries on oral health and associated quality of life, identification of indirect associations between dental caries (including untreated dental caries) and systemic

\footnotetext{
*Correspondence: asabhar5@uwo.ca

${ }^{1}$ Division of Periodontics, Schulich School of Medicine and Dentistry, DSB 0156A, Western University, 1151 Richmond St., London, ON N6A 5C1, Canada

Full list of author information is available at the end of the article
}

health are of potential interest but have received little attention [3].

Associations have been more studied between periodontitis and systemic diseases and the contribution of oral inflammation and microbiota to diseases such as atherosclerosis, diabetes mellitus, pneumonia, chronic obstructive pulmonary disease, rheumatoid arthritis (RA) and Alzheimer disease (AD) [4-6]. In addition to epidemiologic evidence, laboratory and animal studies provide biological plausibility for periodontal-systemic associations $[7,8]$.

While both dental caries and periodontitis are biofilm-mediated diseases, the pathogenesis of dental caries is complex and multifactorial and differs from 
periodontal disease. Dental caries is a biofilm-mediated disease with multiple contributing factors that drives net localized demineralization of the teeth [9]. The plausibility of systemic consequences from untreated dental caries and mechanistic role of the associated oral microbial-inflammatory process in these associations requires further inquiry through human and animal studies. The ability of oral microbiome to spread into systemic circulation from dental caries is plausible and would parallel mechanisms already studied for periodontal disease. In dental caries, involvement of root canal space or marginal periodontium are the most likely pathways for direct systemic extension of oral microbiota [10]. Host factors and pathogenic traits in oral microbiota can promote dental caries and increase the likelihood of oral-systemic spread. Such factors would include diseases [11] and medications [12] that result in reduced saliva production, adhesin expression in S.mutans for collagen binding [13-15], dysbiosis of the oral microbiota $[16,17]$, genetic factors that predispose to dental caries and share common mechanistic underpinnings with systemic diseases [18].

The hypothesis of systemic spread of oral microbiota from carious lesions is reasonable but mechanisms by which systemic diseases exacerbate dental caries requires considerable future research. Metabolic diseases such as diabetes and obesity share various common environmental determinants with dental caries, including hyperglycemic state and high-carbohydrate/ sugar-rich diet [19]. Our current understanding of metabolic disease-dental caries associations and use of animal models [20-27] can serve to expand understanding of associations between dental caries and other systemic diseases. Animal models allow for study of systemic variables in dental caries due to the ability to longitudinally study disease phenotype within a reasonably short time frame.

This scoping review compiled and evaluated recent evidence from animal and clinical human studies that assessed associations between dental caries and systemic diseases and potential mechanisms for such associations. Specifically, a scoping review was undertaken to establish areas in which evidence on associations between dental caries and systemic diseases is available [28].

\section{Methods}

\section{Data sources}

An electronic search was conducted by a health sciences librarian (ES) in June 2021 in PubMed, Embase and Cochrane Central Register for Controlled Trials. Results were limited to articles published from 2010 to 2020 in the English language.

\section{Search strategy}

The following search strategy in PubMed utilized both keyword terms in the title and abstract fields as well as Medical Subject Headings (MeSH) to identify possible qualifying articles: (((((“dental caries" [MeSH Terms]) OR caries[Title/Abstract]) OR carious lesions[Title/ Abstract]) OR carious lesion[Title/Abstract])) AND

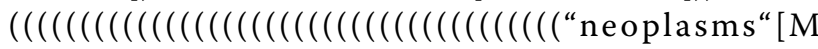
eSH Terms]) OR cancer[Title/Abstract]) OR metabolic syndrome[Title/Abstract]) OR "metabolic syndrome"[MeSH Terms]) OR obesity[Title/Abstract]) OR "obesity"[MeSH Terms]) OR cardiovascular diseases[Title/Abstract]) OR cardiovascular disease[Title/ Abstract]) OR "cardiovascular diseases"[MeSH Terms]) OR myocardial infarction[Title/Abstract]) OR heart disease[Title/Abstract]) OR heart diseases[Title/ Abstract]) OR diabetes[Title/Abstract]) OR “diabetes mellitus"[MeSH Terms]) OR atherosclerosis[Title/ Abstract]) OR cerebrovascular disease[Title/Abstract]) OR cerebrovascular diseases[Title/Abstract]) OR "cerebrovascular disorders"[MeSH Terms]) OR asthma[Title/Abstract]) OR "asthma"[MeSH Terms]) OR pneumonia[Title/Abstract]) OR "pneumonia"[MeSH Terms]) OR chronic obstructive pulmonary disease[Title/Abstract]) OR "pulmonary disease, chronic obstructive"[MeSH Terms]) OR allergies[Title/Abstract]) OR "hypersensitivity"[MeSH Terms]) OR "respiratory tract diseases"[MeSH Terms]) OR arthritis[Title/ Abstract]) OR "arthritis, rheumatoid"[MeSH Terms]) OR Alzheimer Disease[Title/Abstract]) OR “Alzheimer's Disease" [MeSH Terms]) OR dementia[Title/Abstract]) OR "dementia"[MeSH Terms]) OR "inflammatory bowel diseases"[MeSH Terms]) OR crohn disease[Title/ Abstract]) OR "osteoporosis"[MeSH Terms]) OR osteoporosis[Title/Abstract]) OR "joint diseases"[MeSH Terms]) OR systemic[Title/Abstract]).

This search was translated and updated for Embase and Cochrane Central Register of Controlled Trials accordingly.

\section{Data filtering}

The results obtained using search strategy described above were deduplicated and further managed in an online workflow management system for scientific reviews (https://www.covidence.org/). After removal of duplicates, titles were examined by one author (AS) and articles unrelated to dental caries were removed. For retained articles, after title-based filtering, their eligibility was assessed by abstract-based filtering by two authors (AS and FAS). If articles were considered unrelated to scope of this review using criteria identified below, they were excluded. Articles were removed for various 

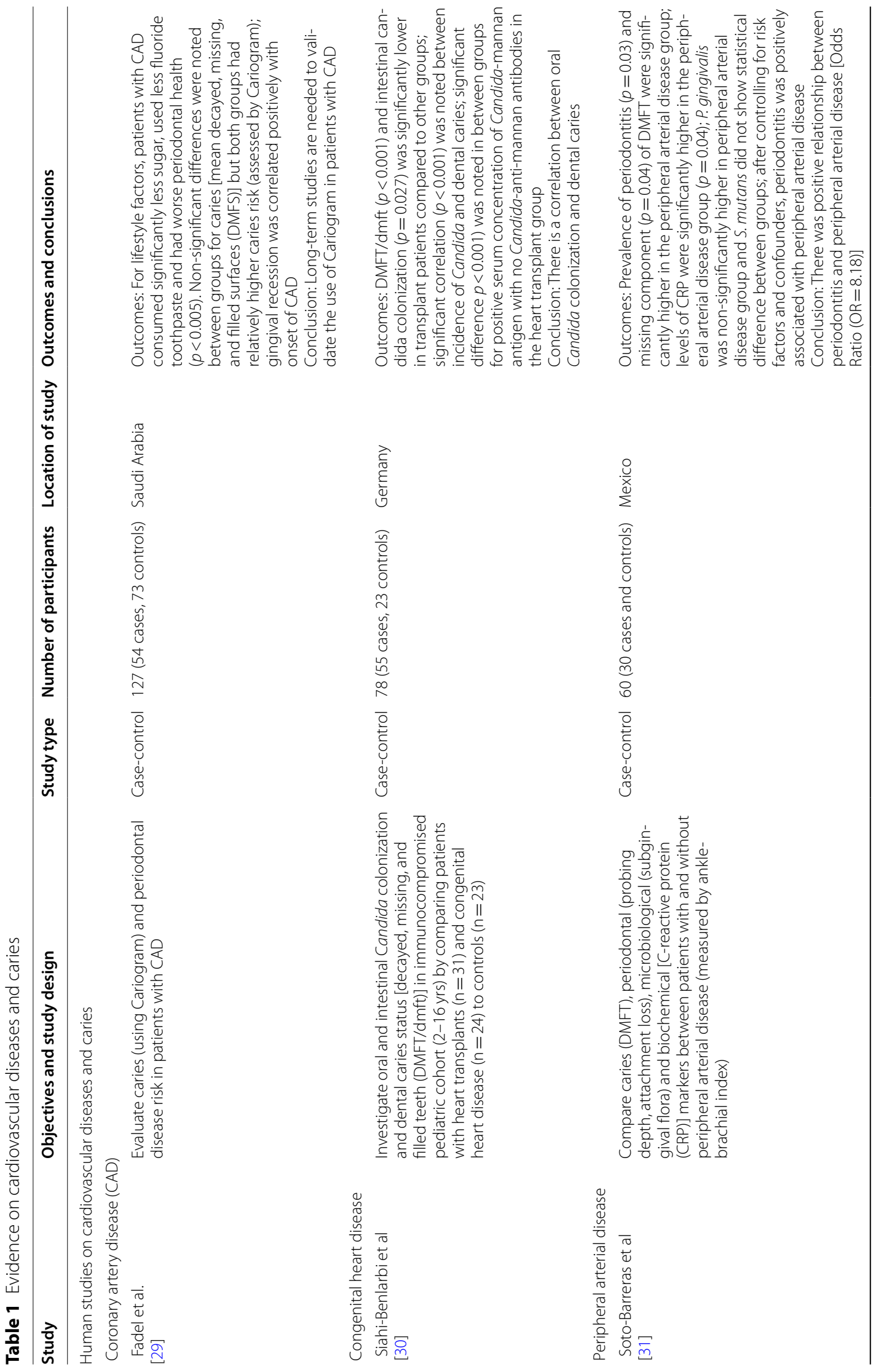

悹

$\stackrel{\frac{3}{\pi}}{\frac{\pi}{2}}$

$\frac{\pi}{\frac{\pi}{0}}$

m

凹్ర

$\underset{\substack{n \\ \infty}}{\infty}$

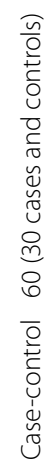

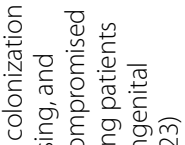

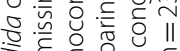

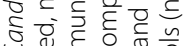

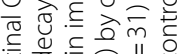

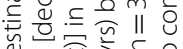

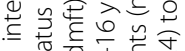

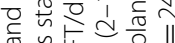

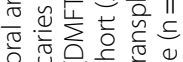

잉

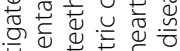

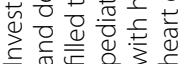
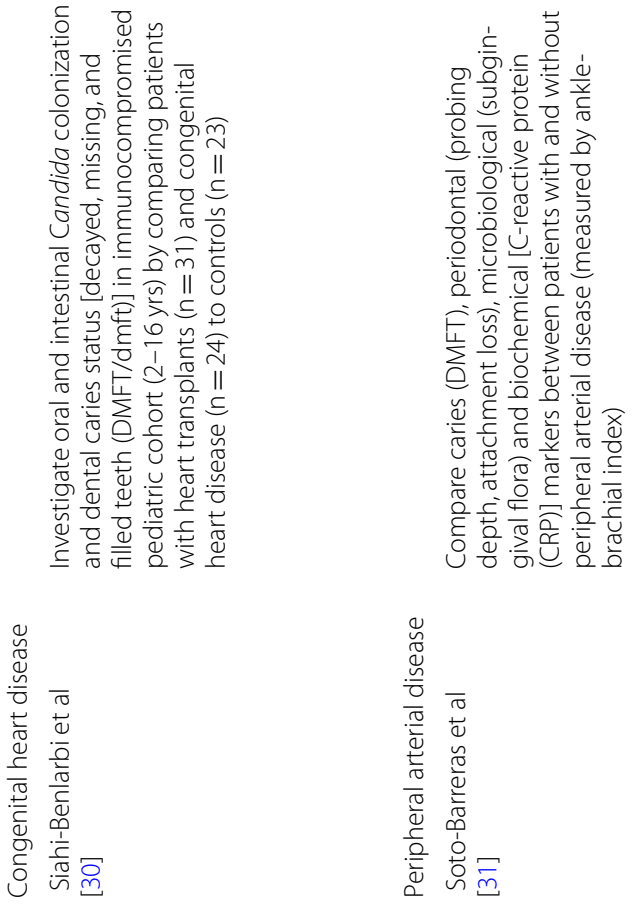


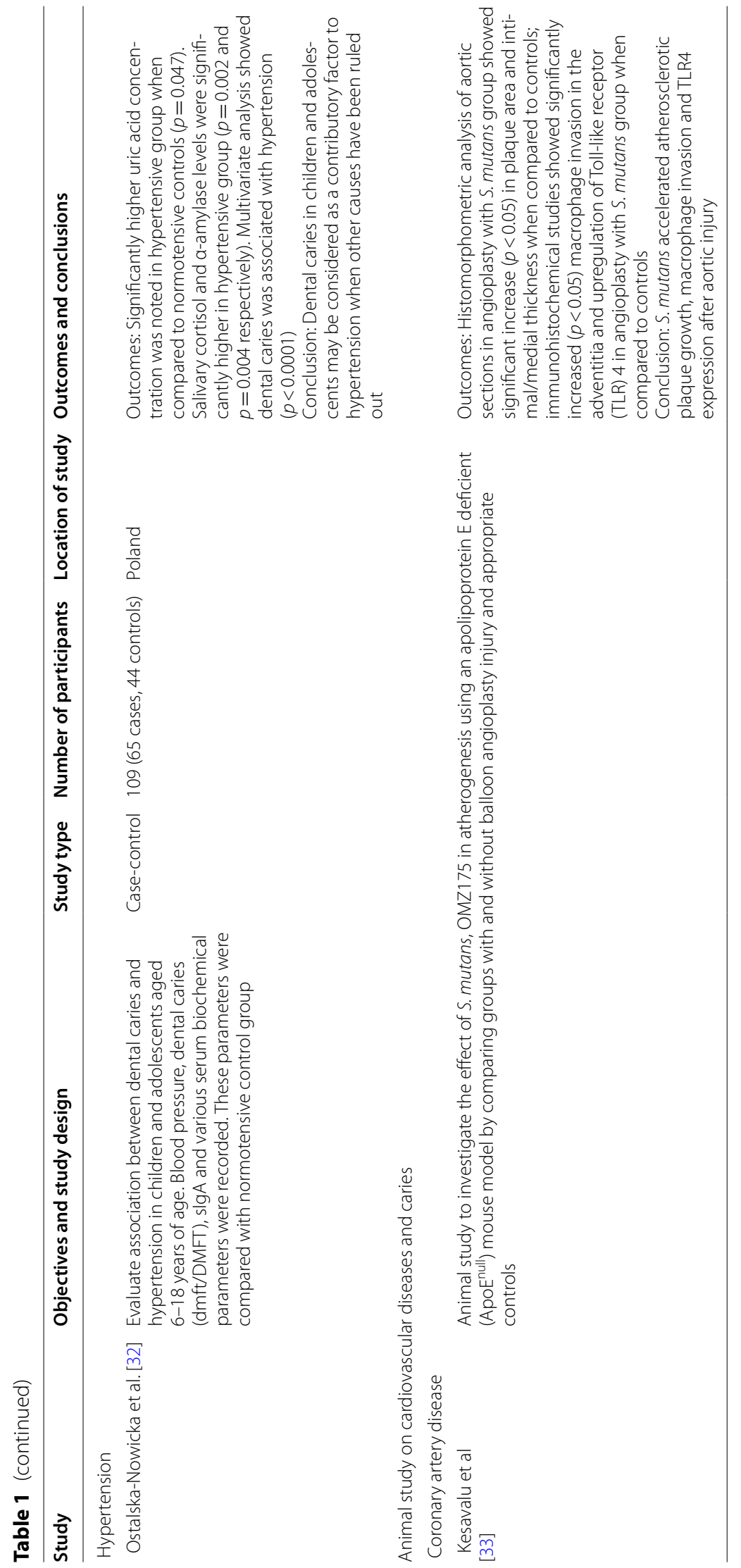




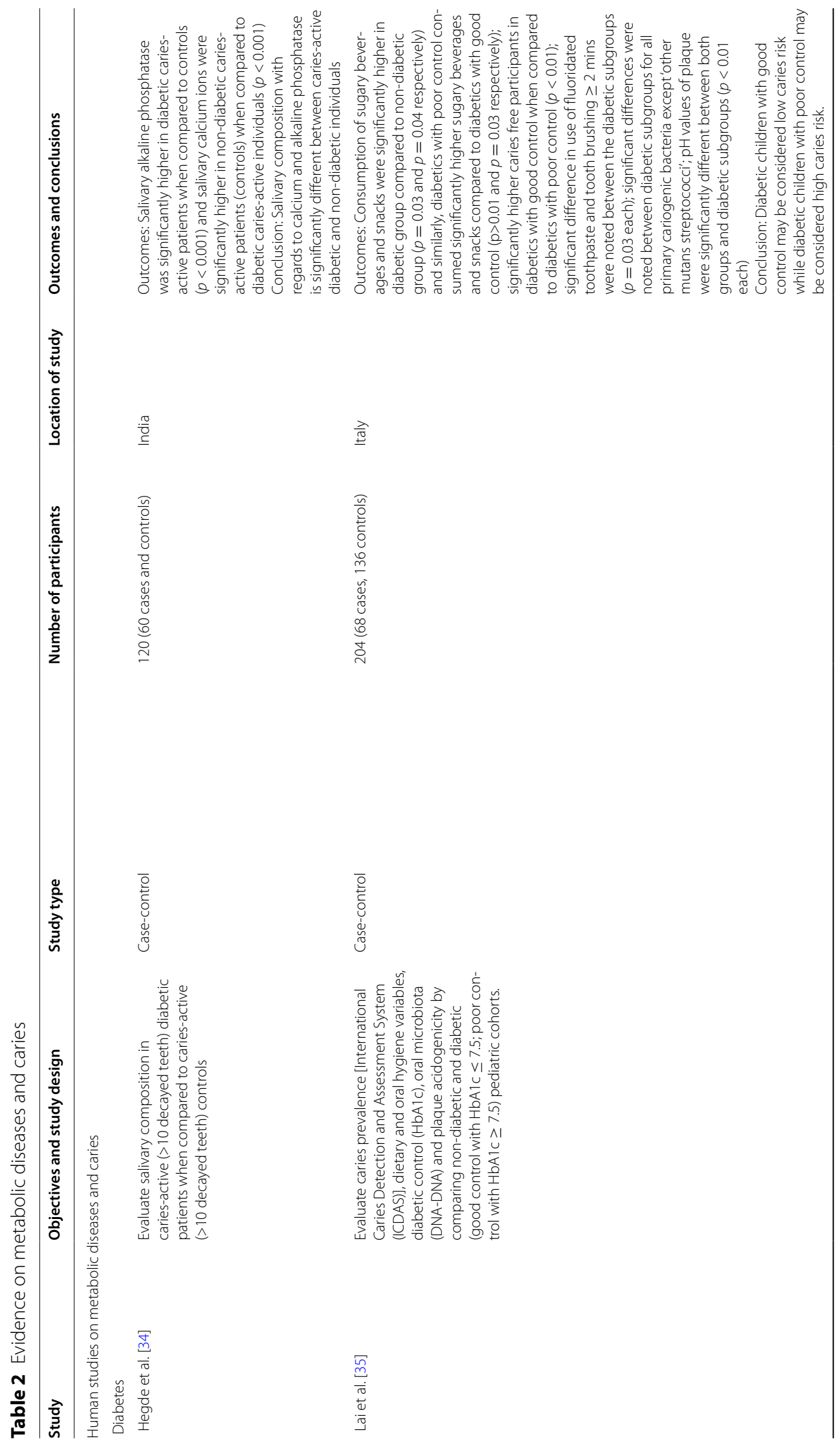




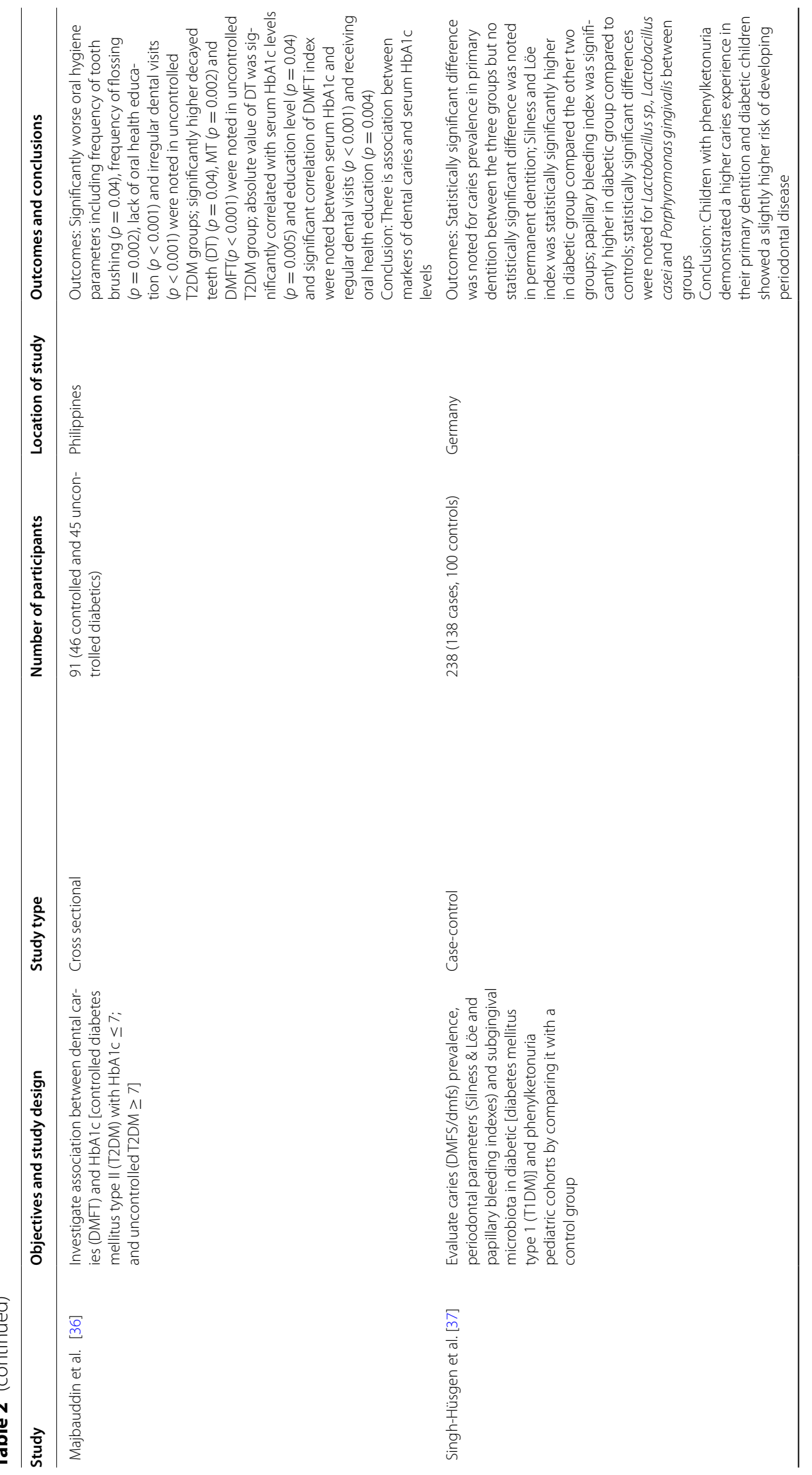




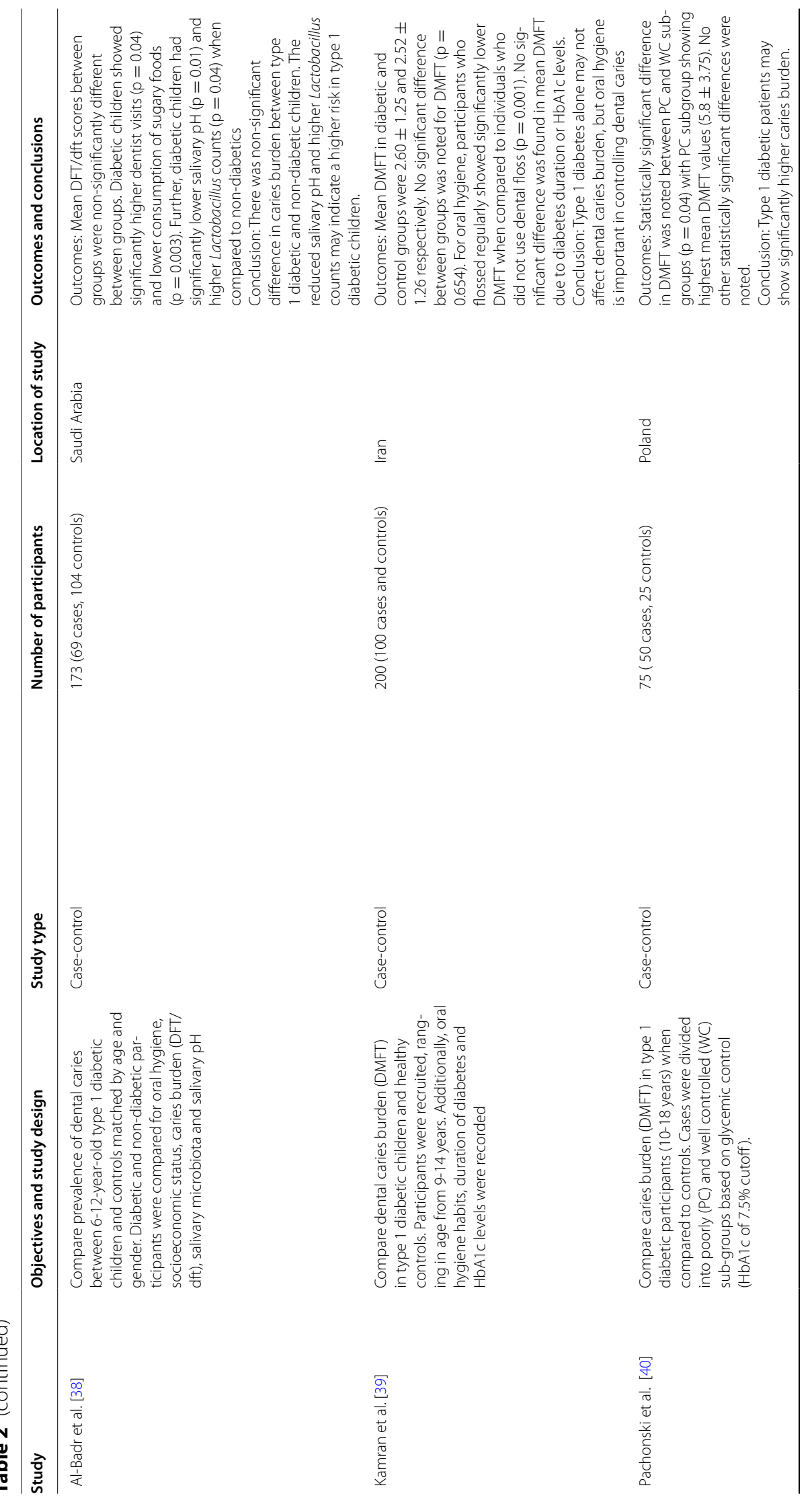




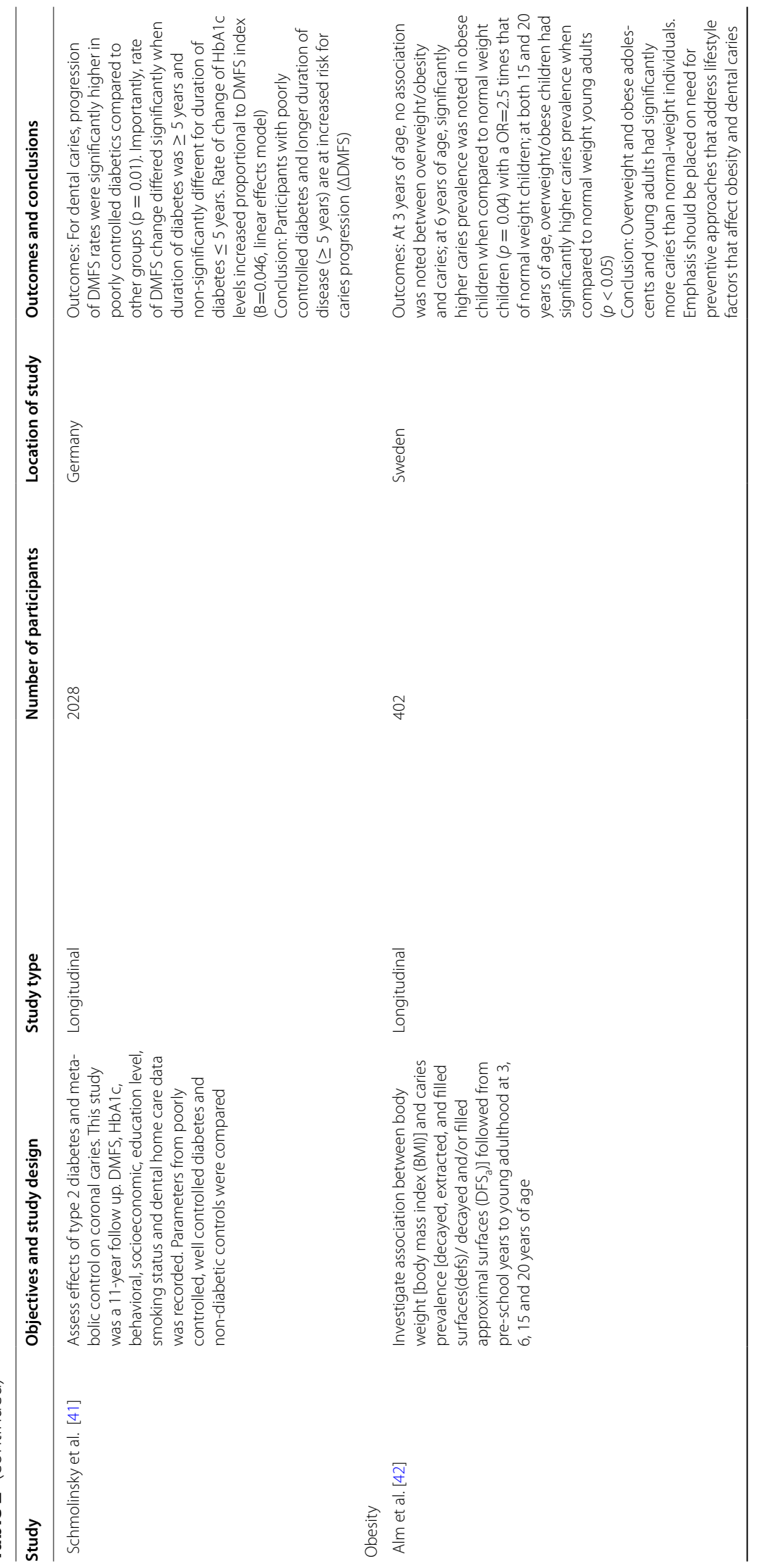




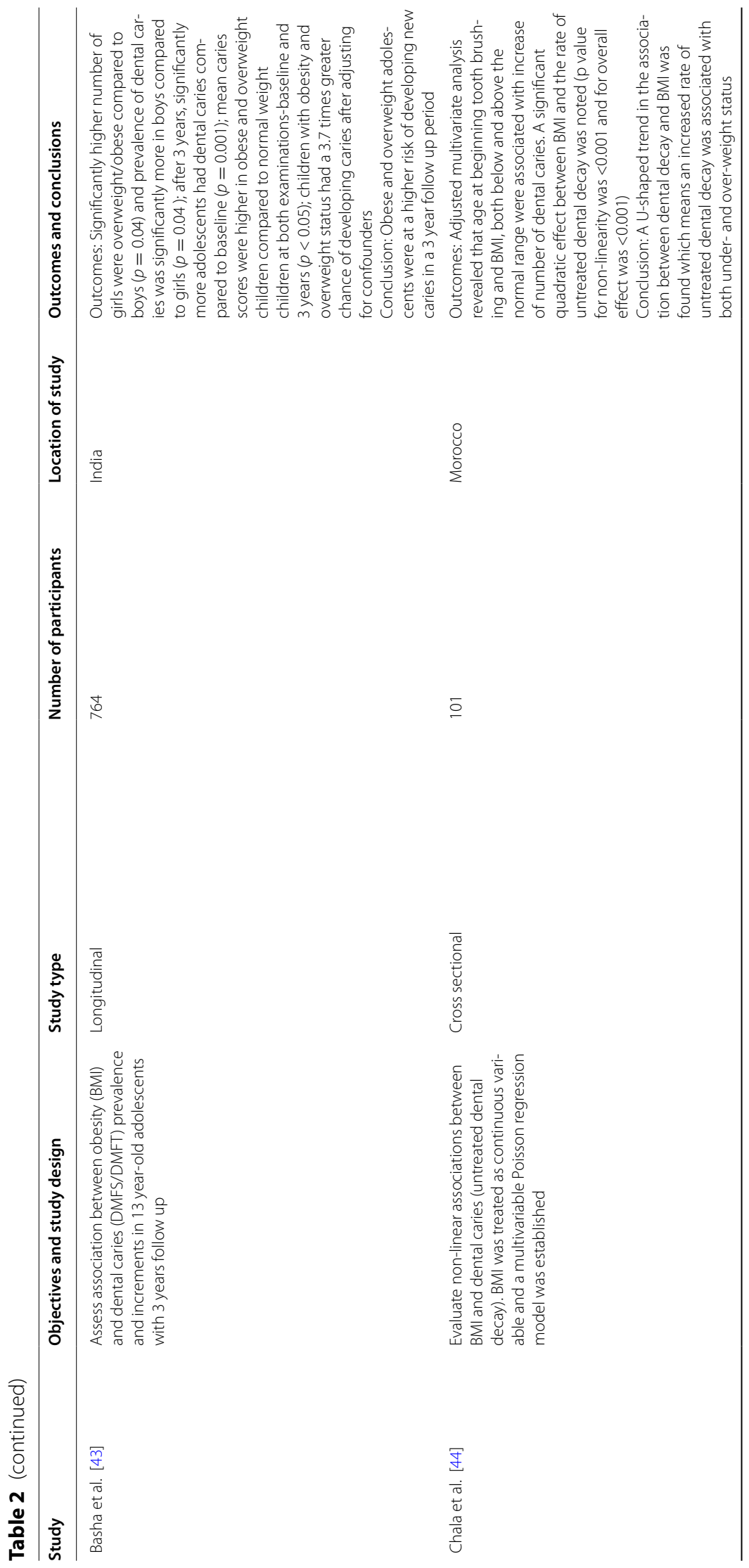




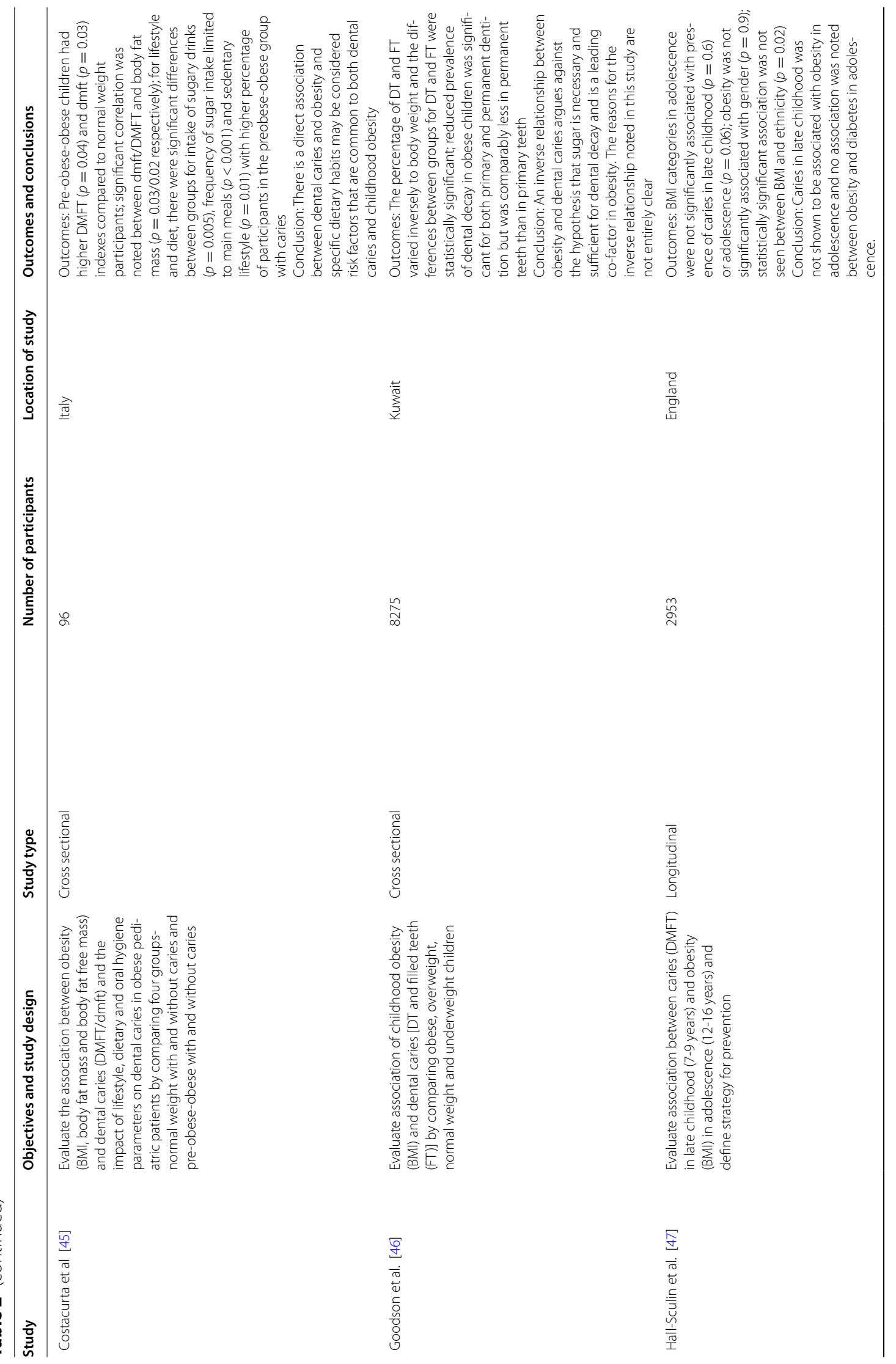




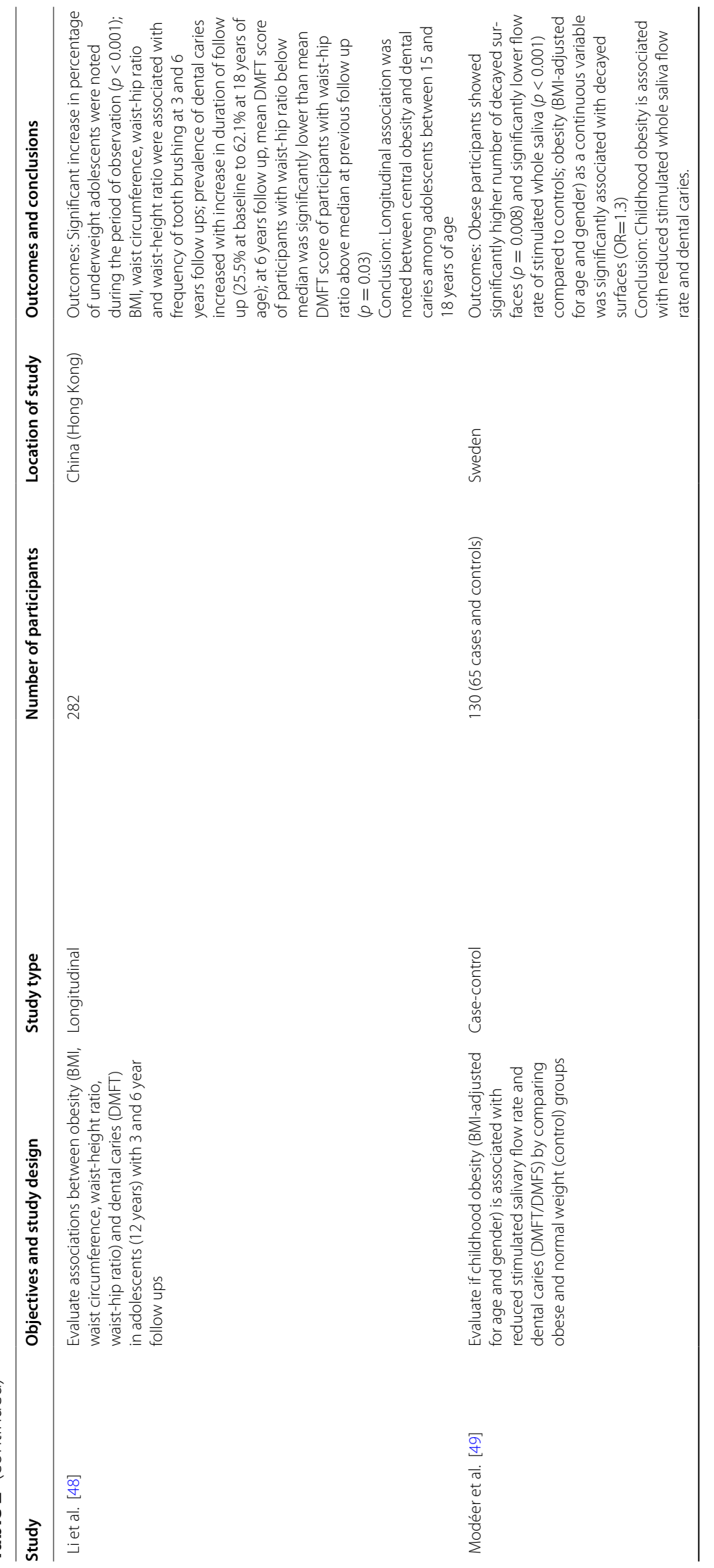




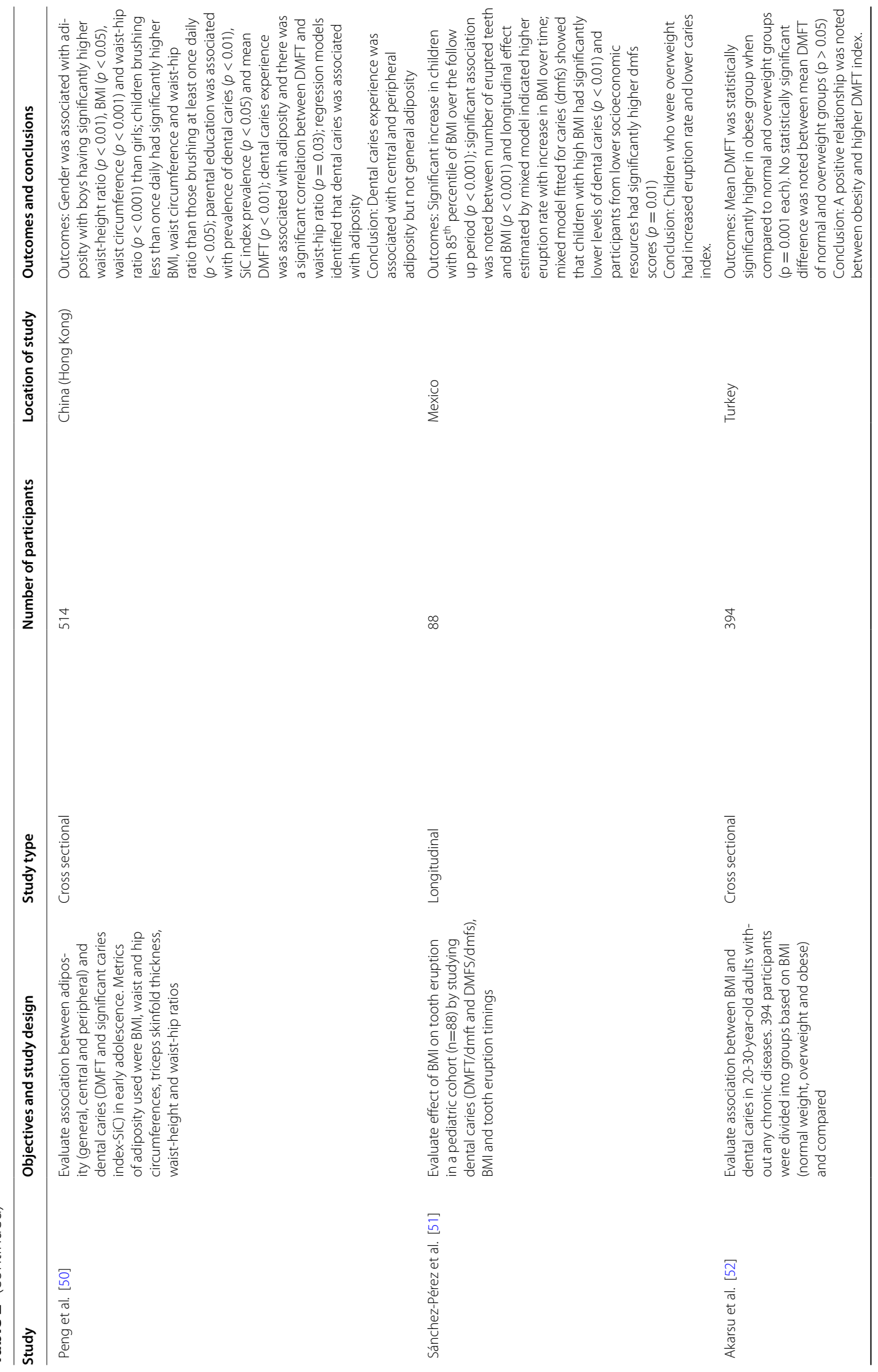




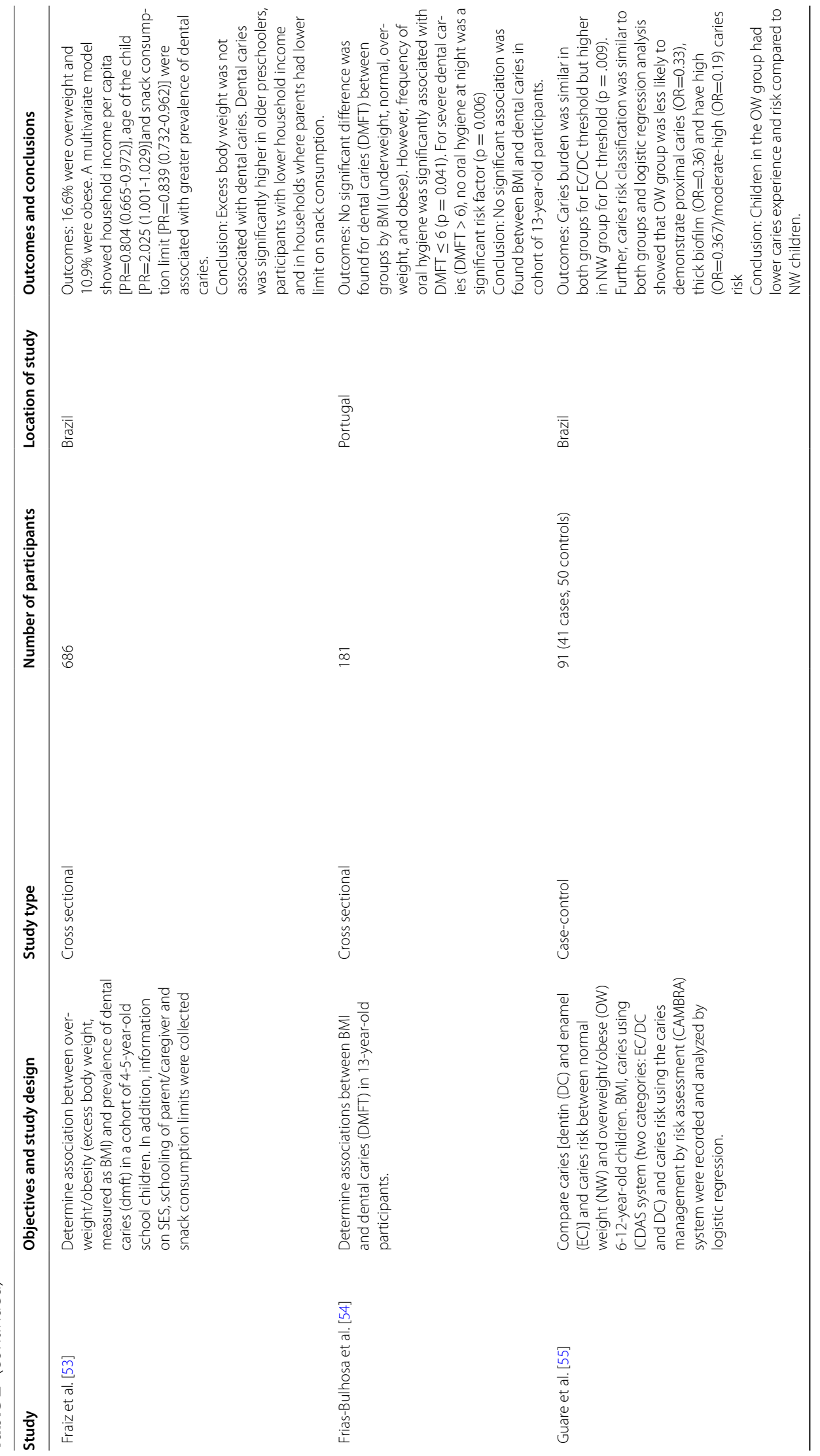




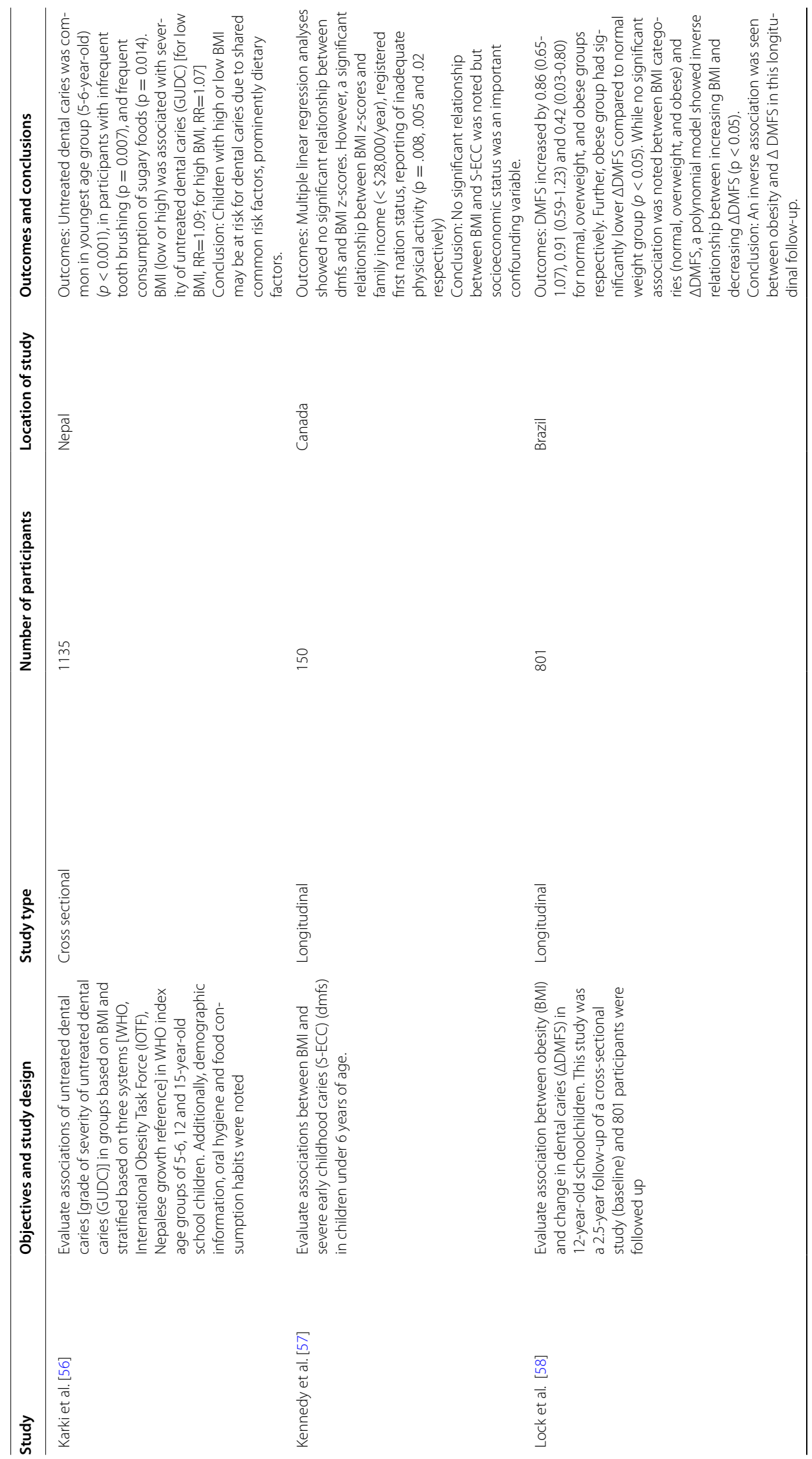




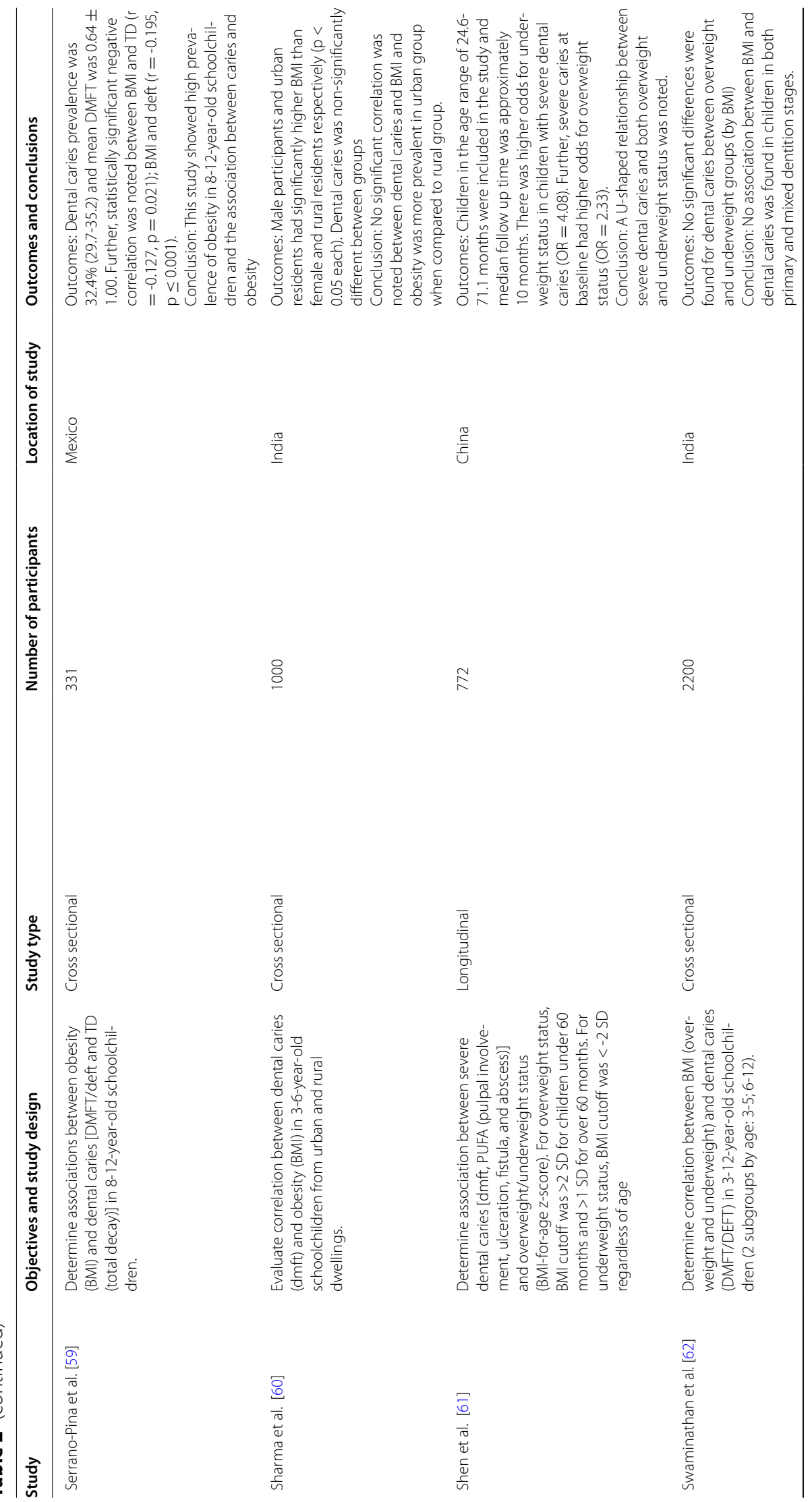




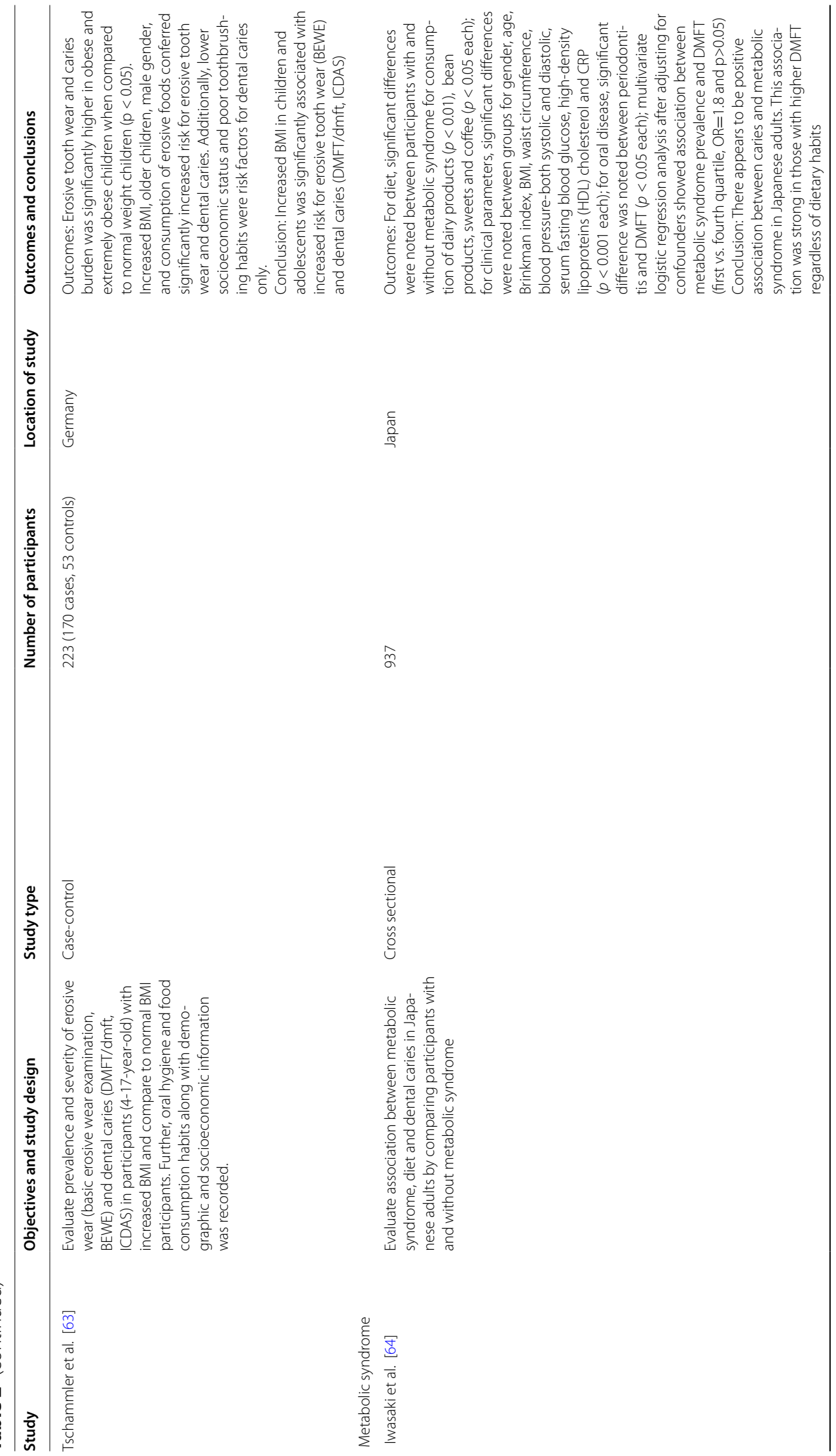




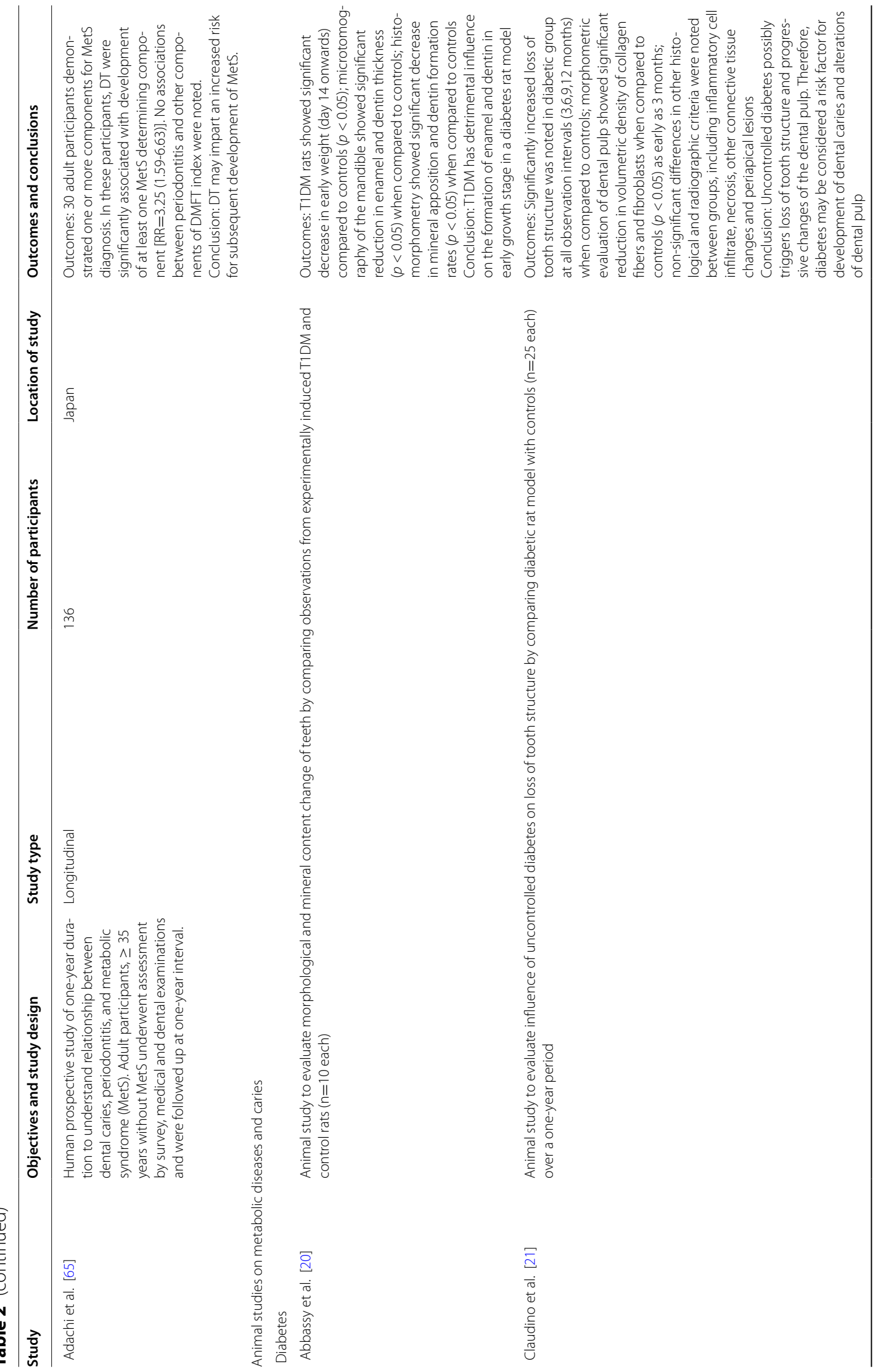




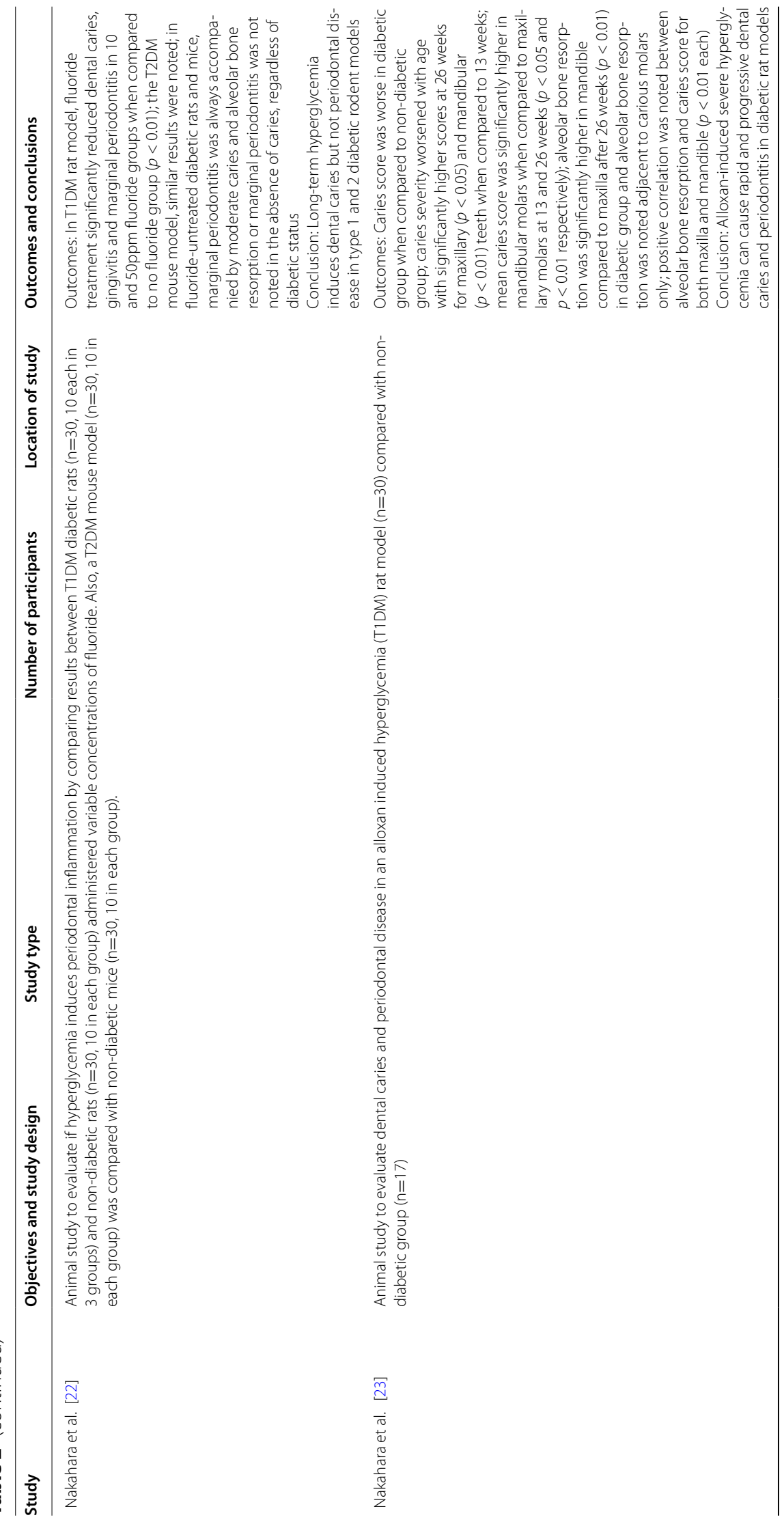




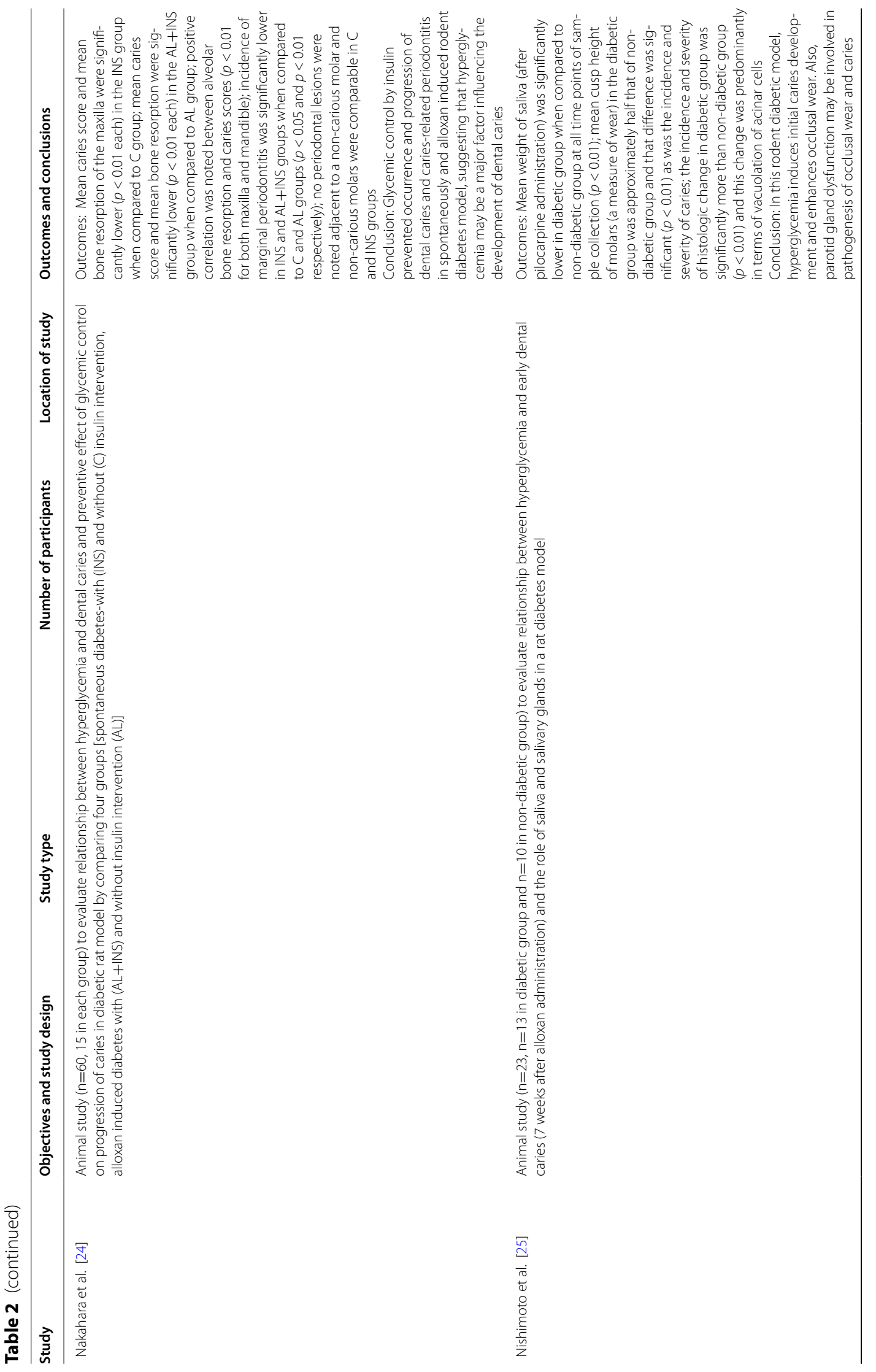




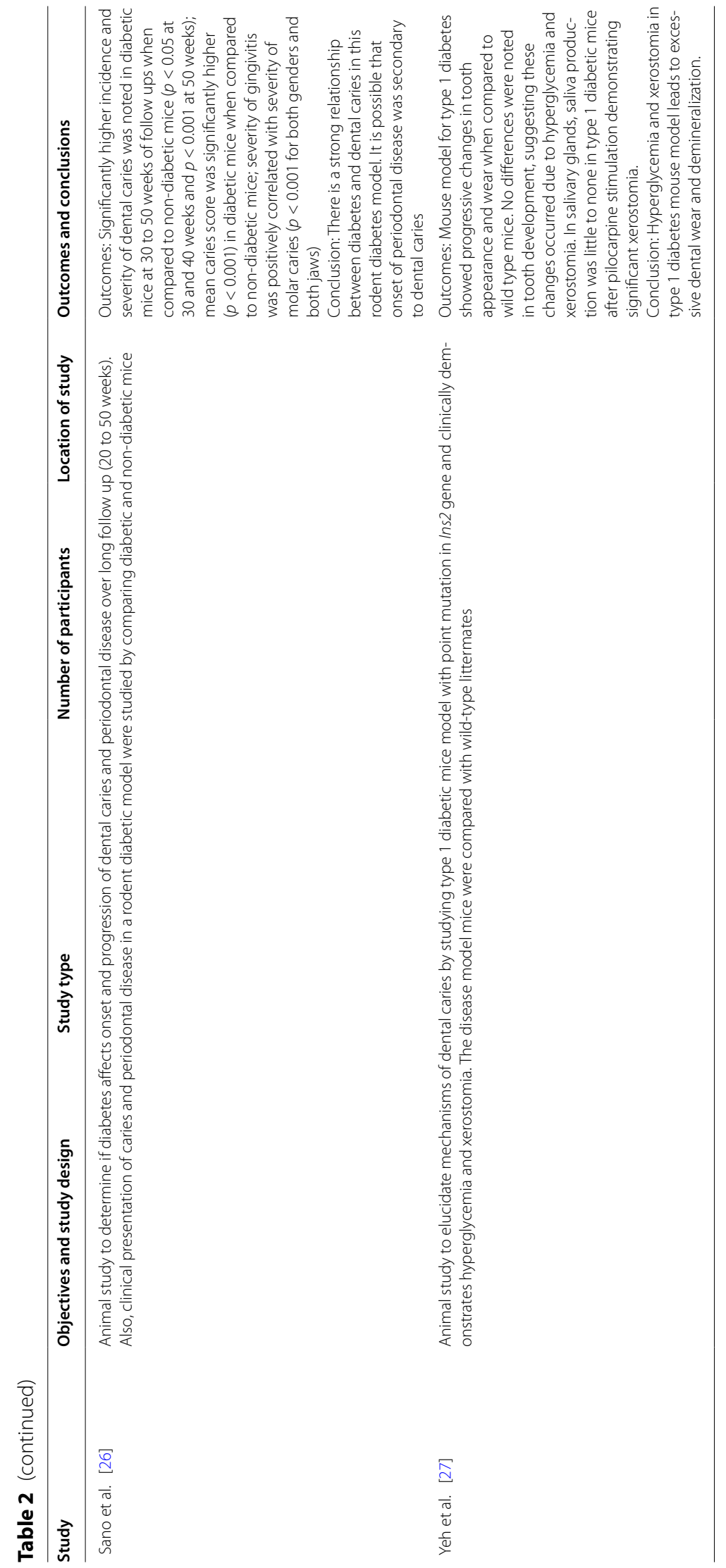




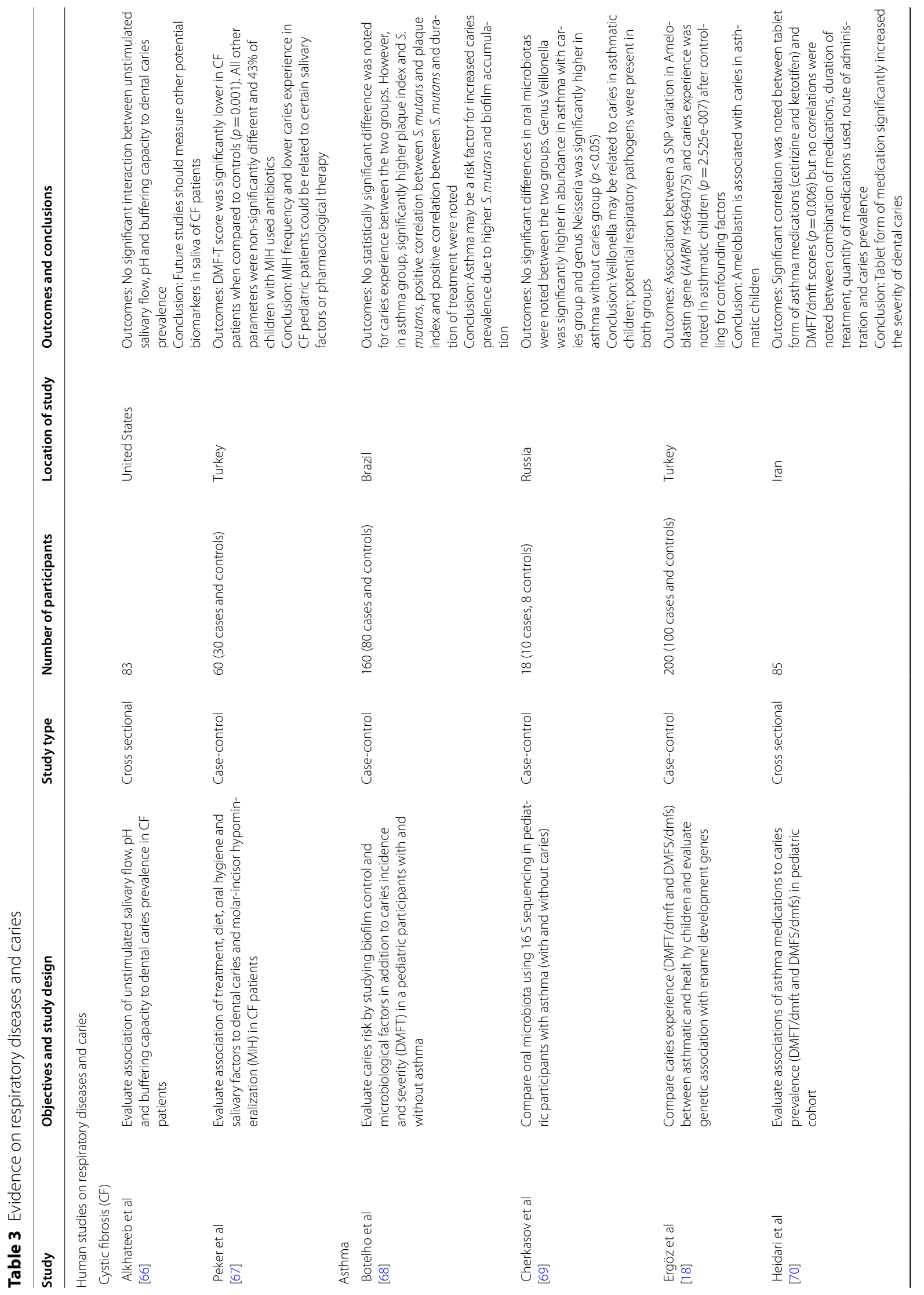




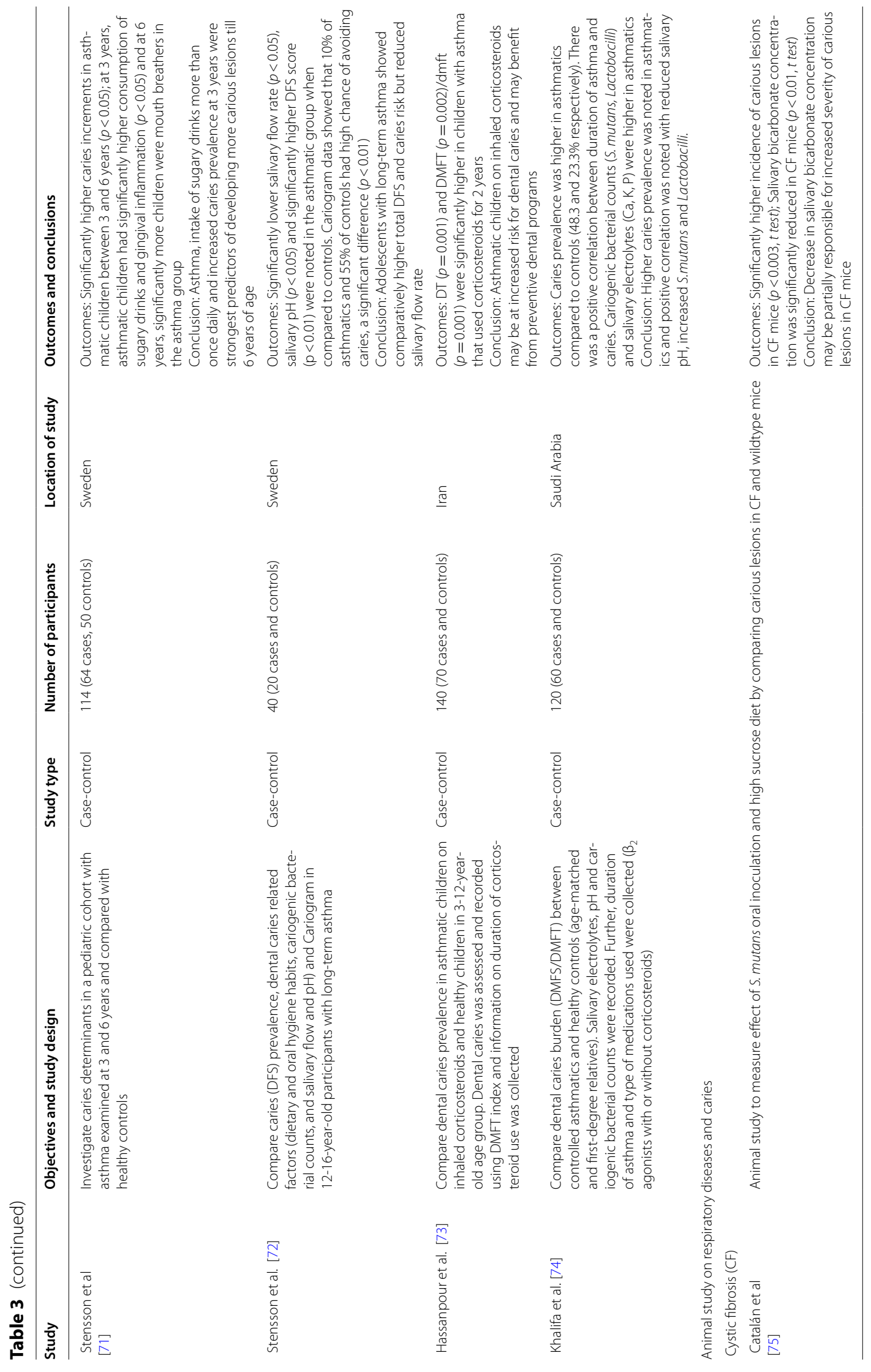




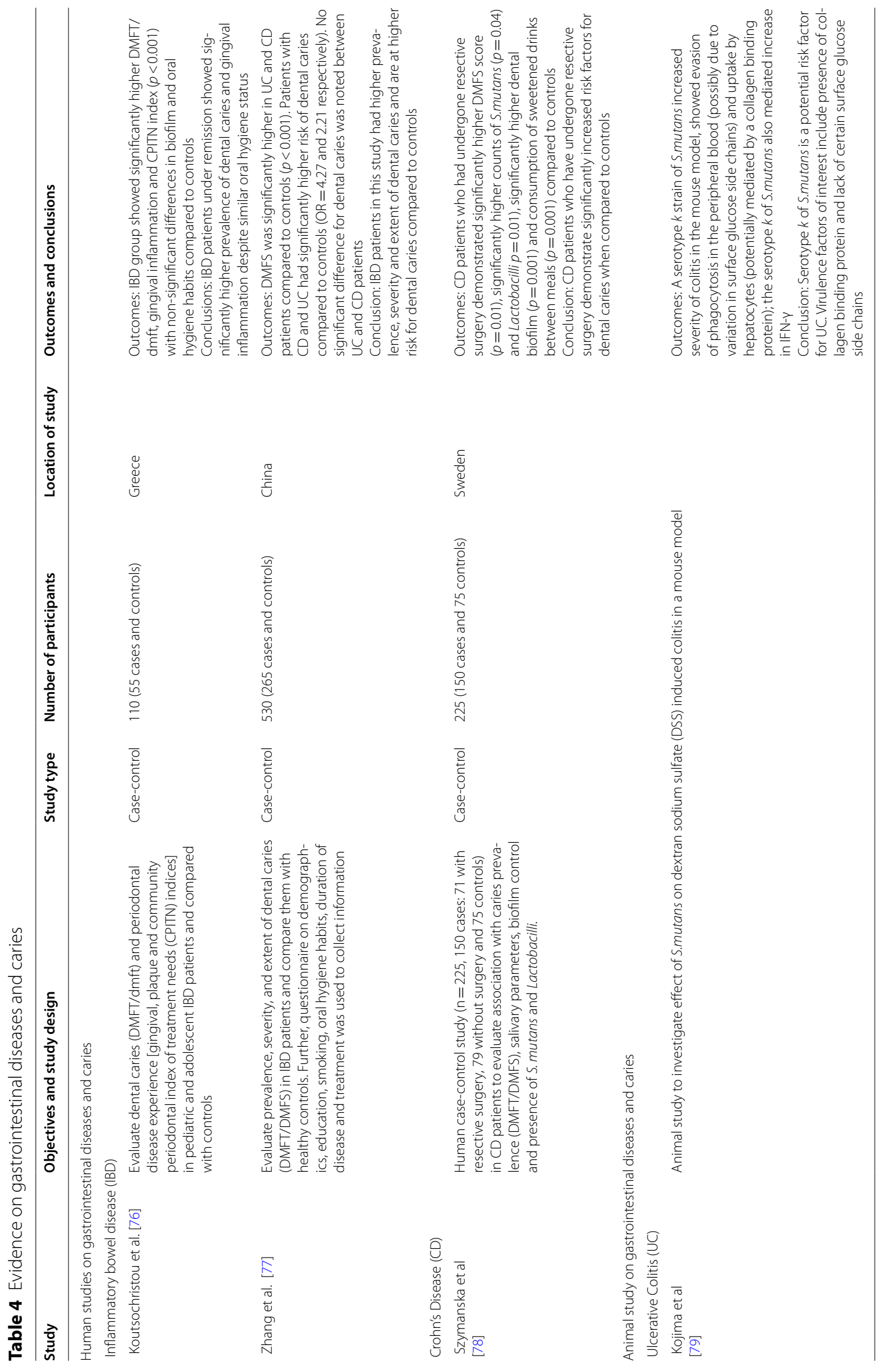




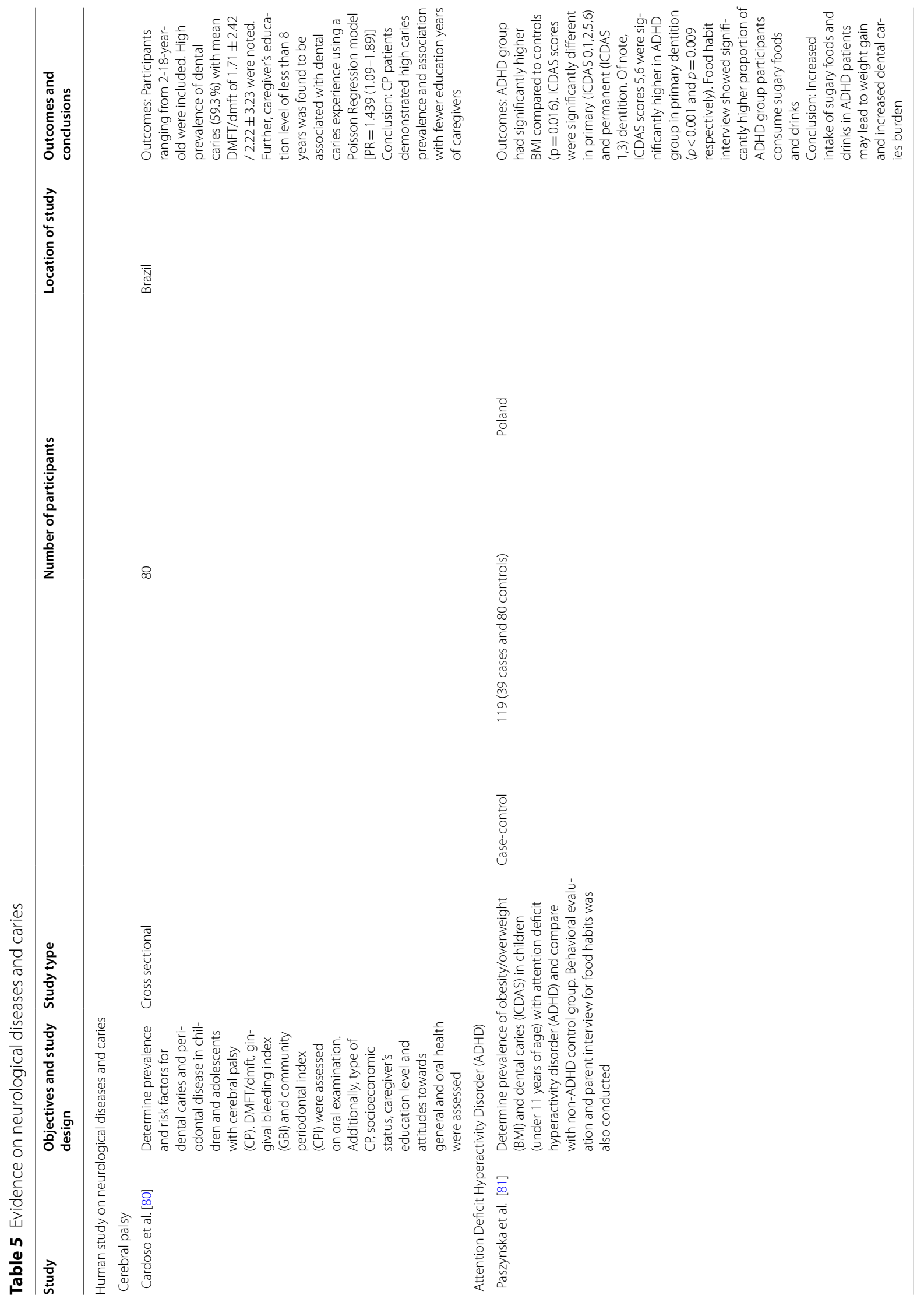




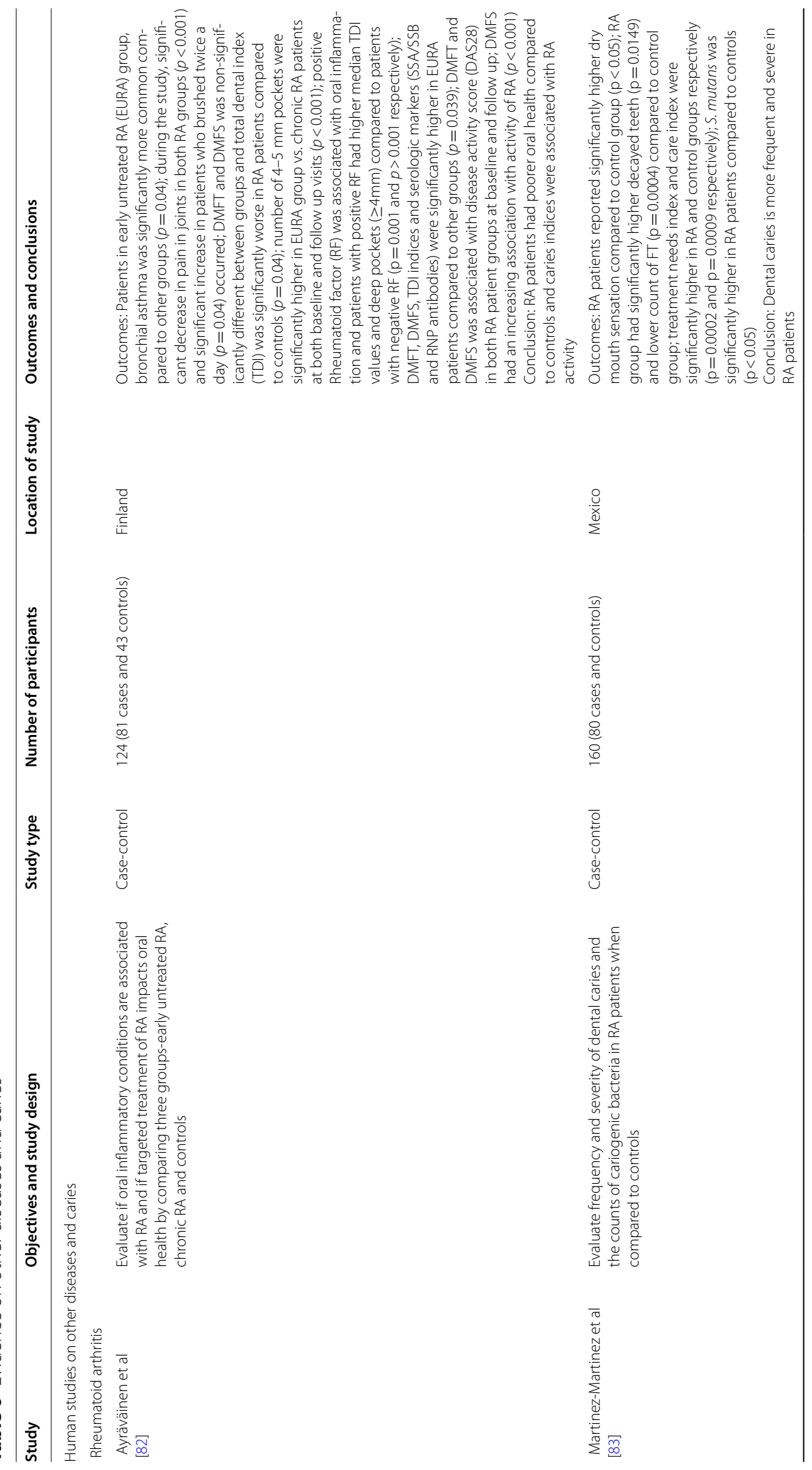




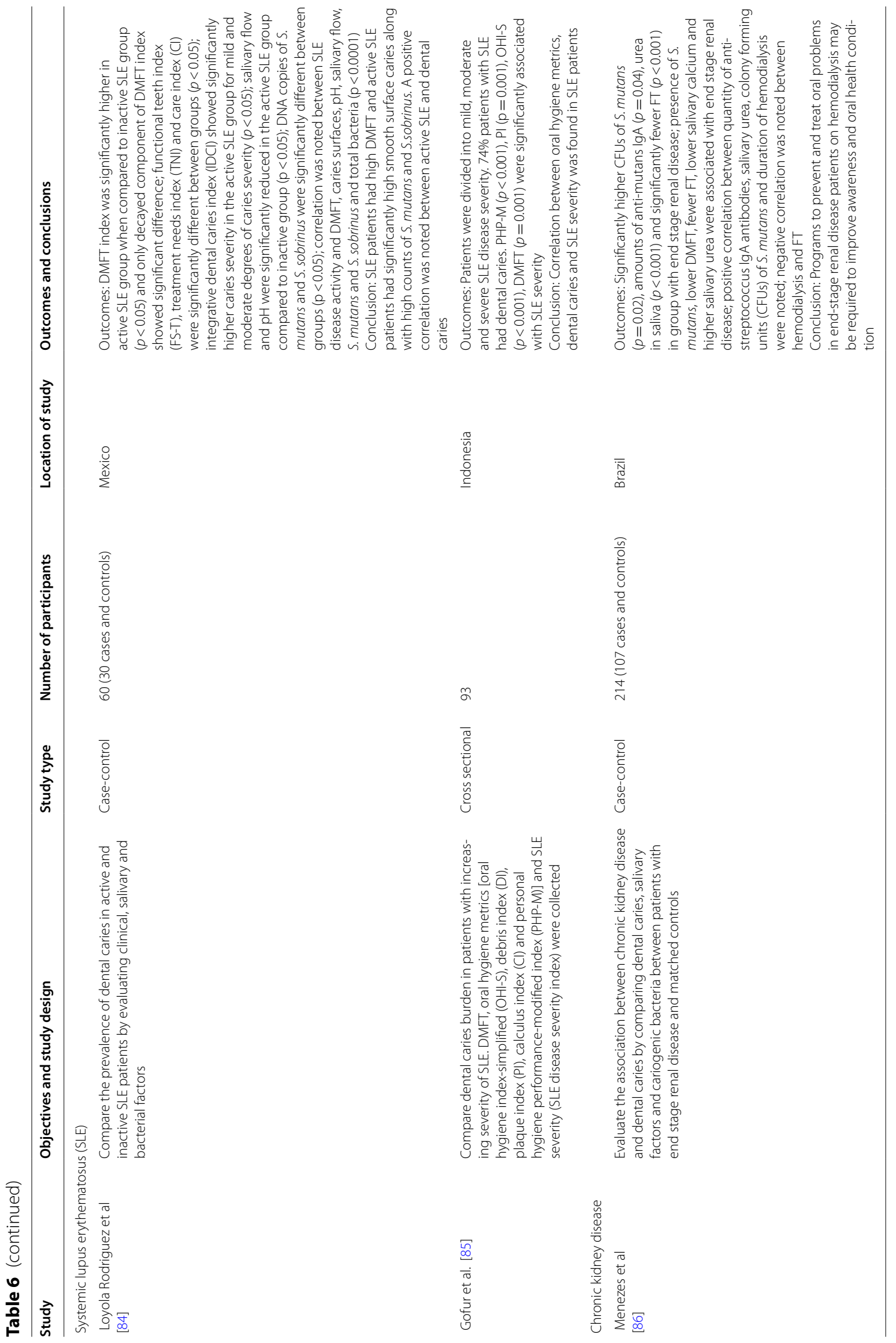


technical reasons such as wrong outcome measures, inadequate statistical information, narrow participant enrollment such as studies with one gender enrollment. Articles that were published in potentially predatory journals were also removed if the corresponding journal was listed in Beall's list (https://beallslist.net/) and was not listed in the Directory of Open Access Journals (https://doaj.org/). When articles were on the topic of associations between dental caries and systemic diseases, systematic and retrospective reviews and data analysis of health records were excluded. Studies were also excluded if dental caries was not the primary variable and was studied as a subset of oral health and/or systemic disease was studied as a subset of overall health. In addition, infective endocarditis was removed from our search criteria as it has been extensively reviewed previously.

Clinical human and animal studies were included where associations between dental caries and a systemic disease were explored or a potential mechanism was elucidated and they did not meet any of the aforementioned exclusion criteria. Using the filtering criteria above and after full-text screening by two authors (AS and FAS) studies were included in the summary tables and additional studies were included in the review to support evidence. If one author agreed to inclusion after full-text screening, the corresponding article was included.

Individual studies were tabulated and brief description of the following parameters were provided: name of first author, year of publication, number of participants, country of study participants, study groups (treatment and control), study population (human or animal), objective of the study, study design, outcomes including statistical parameters and conclusions (Tables 1, 2, 3, 4, 5 and 6).

\section{Results}

After deduplication, the initial search yielded 4817 results. 404 full-text articles were assessed for eligibility and further 133 studies were excluded for various technical reasons described above. The remaining 271 full-text articles were assessed, and after excluding studies where dental caries and/or systemic disease was not the primary variable of interest, and excluding literature reviews and data analysis of health records, 67 studies were included in the summary tables.

Studies were included on the following systemic diseases: coronary artery disease (Table 1), congenital heart disease (Table 1), peripheral artery disease (Table 1), hypertension (Table 1), diabetes (type I and II) (Table 2), obesity (Table 2), metabolic syndrome (Table 2), cystic fibrosis (Table 3), asthma (Table 3), ulcerative colitis (Table 4), Crohn's disease (Table 4), cerebral palsy (Table 5), attention deficit hyperactivity disorder (Table 5), rheumatoid arthritis (Table 6), systemic lupus erythematosus (Table 6) and chronic kidney disease (Table 6). A total of 56 human studies and 11 animal studies were included in the summary tables. Relatively, more studies on metabolic diseases (type I diabetes, type II diabetes, obesity and metabolic syndrome) were included in this review (40 total, 32 human and 8 animal) when compared to evidence found in other disease groups. Within 56 human studies included, 29 studies were case-control, 17 were cross sectional and 10 were longitudinal studies.

\section{Discussion}

\section{Cardiovascular diseases and caries}

Dental caries experience was not significantly different when compared to controls in human studies of coronary and peripheral arterial disease, but overall oral inflammatory burden was significantly higher in cases due to increased burden of periodontal disease [29, 31]. Additionally, one study compared dental caries in patients with congenital heart disease with and without heart transplants, thus comparing the effect of immunocompromised status on dental caries [30]. Interestingly, transplant group had significantly lower caries experience when compared to group without heart transplant. The authors explained this difference based on the possibility of increased attention to dental care in children with heart transplants. While frequent antibiotic intake could explain this observation, in this study it was an exclusion criteria due to possible confounding of results.

Other studies have evaluated attitudes of dentists and of parents of children who are at high risk for infective endocarditis [87] including those with congenital heart disease [88-90]. These findings suggest that specialists in pediatric dentistry and general practitioners who regularly treat children are more informed about appropriate dental care for children with congenital heart disease. There needs to be a concerted effort between the dentists, medical providers and parents to encourage prevention to achieve favorable outcomes in children at high risk for infective endocarditis due to their cardiac conditions.

More atherosclerotic plaque and presence of genomic DNA from S.mutans was found in a group of ApoE $E^{\text {null }}$ mice, infected by intravenous injection (tail vein) of S.mutans and subjected to balloon angioplasty injury compared to non-injured mice (controls) [33]. Immunohistochemically, sections of atherosclerotic plaque from injured group showed macrophage invasion in the tunica adventitia of aorta and upregulation of TLR4. Further studies demonstrated that collagen-binding protein (cnm) is important for invasive potential of $S$.mutans [13]. Specifically, it was found that serotype $f$ strain OMZ175 of $S$. mutans has this capability [91]. These 
studies further explores the invasive nature of serotype $f$ strain OMZ175 of $S$. mutans in a model of cellular injury.

While experimental data on the invasive potential for certain serotypes of $S$. mutans exists, expert panels do not recommend antibiotic prophylaxis prior to all dental procedures. The rationale behind such an approach is that the likelihood of developing infective endocarditis due to a bacteremia from dental procedure is significantly lower than bacteremia from routine at-home toothbrushing and flossing. Furthermore, it is not clear if antibiotic prophylaxis prior to dental procedures will prevent all potential for infective endocarditis secondary to dental procedures. In this scenario, the risk-benefit analysis appears to be of low benefit and high risk, taking into account the potential for antibiotic resistance. A recent meta-analysis of randomized controlled trials showed vesicoureteral reflux patients treated with antibiotic prophylaxis were 6.4 times more likely to develop a multidrug-resistant urinary tract infection [92]. It is reasonable to use conclusion from this study and exercise caution in frequent antibiotic prophylaxis for dental procedures till directly applicable results are available in the dental literature. While caution must be exercised, there are exceptions and it is thought that patients in certain high-risk categories may benefit from antibiotic prophylaxis [93].

Ostalska-Nowicka et al. found association of dental caries with primary hypertension in a case-control study [32]. Authors found significantly higher salivary evening cortisol levels, uric acid concentrations in participants with caries and also found correlation between dental caries and microalbuminuria. These biochemical parameters are of importance in pathophysiology of hypertension and indicative of activation of renin-angiotensin system and reorganization of endothelium [32]. Considering the multifactorial nature of dental caries and hypertension, future studies that evaluate social determinants, diet and systemic inflammation secondary to oral and gastrointestinal dysbiosis may provide valuable input into common mechanisms of dental caries and primary hypertension [94-97].

\section{Metabolic disorders and caries Diabetes}

Several human clinical studies and animal studies have addressed the connection between dental caries and diabetes. Outcomes other than caries were also studied, including salivary composition, microbiology and periodontal status. Hegde et al. found that caries active participants who were diabetic demonstrated significantly reduced salivary calcium and significantly increased alkaline phosphatase when compared to caries active non-diabetic participants [34]. Similarly, Al-Badr et al. demonstrated that children with type 1 diabetes had significantly lower salivary $\mathrm{pH}$ and higher counts of Lactobacilli. Reduced salivary $\mathrm{pH}$ and higher lactobacilli count are crucial factors for demineralization of teeth and exacerbation of dental caries [38]. Reduction in salivary $\mathrm{pH}$ and increase in counts of cariogenic microbiota can occur secondary to cariogenic diet and poor plaque control and was demonstrated as such by Kamran et al. [39] and therefore, it is important to emphasize the multifactorial and overlapping nature of dental caries and obesity before drawing conclusions from study of select variables. Furthermore, studies into the association of diabetic control and other parameters of diabetes phenotype with dental caries will increase our understanding of risk stratification and consequently, prevention of dental caries in diabetic patients [40, 41]. Two other studies showed that lifestyle, dietary and oral care factors were significantly different between groups with controlled and uncontrolled diabetes measured by glycated $\mathrm{Hb}[35$, 36]. Similarly, when pediatric cohort with phenylketonuria and those with type 1 diabetes were compared, children with phenylketonuria had significantly higher caries experience [37].

Animal studies used rodent models of diabetes (primarily type 1 diabetes) and hyperglycemia to study its relationship with dental caries and other tooth-related changes [20-27]. Changes in enamel, dentin, pulp and salivary glands with alveolar bone loss were compared, both to control groups and groups with intervention using fluoride application and insulin administration. Consistent results from animal models demonstrated that hyperglycemia in diabetic rodents was associated with increased dental caries [22-26]. In addition, these studies showed that there were histological and morphometric changes in enamel, dentin and pulp in diabetic animals. There were reduction in volume of pulpal connective tissue and enamel and dentin, along with excessive wear of enamel [20, 21, 25, 27]. Salivary histological change included vacuolization in acinar cells and functionally, reduction in saliva production that resulted in xerostomia [25, 27]. Carious lesions positively correlated with gingivitis and periodontitis [23, 26]. Lastly, both fluoride application and insulin administration interventions resulted in reduction of dental caries, marginal gingivitis and periodontitis [22, 24].

\section{Obesity}

Of all systemic diseases, an association between obesity and caries was more robust than noted for other systemic conditions, as documented in twenty-two human clinical studies including eight longitudinal clinical studies. Data from longitudinal studies did not consistently find an association between obesity and dental caries and 
studies with larger samples sizes did not find association between dental caries and obesity [42, 43, 47, 48, 51-53, $57,58,60,62,63]$. In studies where obesity and metabolic syndrome were found to be associated with caries, odds ratio ranged from 1.01 to 3.7 [42, 43, 49, 52, 63-65]. Interestingly, a relationship between low BMI and dental caries was noted and an inverse relationship between overweight status and caries was seen in some studies [44, 46, 58]. Chala et al., through statistical modeling found a U-shaped relationship between BMI and caries, which means that caries was associated with both underweight and overweight status [44] and this U-shaped relationship between BMI and caries has been reproduced in two recent studies. Untreated dental caries can impact overall nutritional status and subsequently BMI. Further, reduction in masticatory efficiency can promote intake of softer foods and increase in dental caries burden [56, 61]. Longitudinal studies are needed to examine relationship between onset and progression of dental caries and their effect on BMI. A study showed significant weight gain in children when teeth with severe dental caries and pulpal involvement were extracted [98]. Mixed results on the association of BMI and dental caries are also indicative of the complex etiologic nature of dental caries. Various factors including access and attitude to dental care, socio-economic status, maternal education, oral habits, diet, biological and microbiological factors interact in caries etiopathogenesis [99]. Additionally, variable definitions and surrogate markers used in association studies further complicate consensus and ability to synthesize reproducible conclusions [100]. An important implication of the mixed results observed for caries association with systemic conditions likely results in lack of reliable, reproducible risk prediction tools for dental caries [101]. It appears that past and current caries experience along with frequent follow ups and use of fluoride for caries prevention remain the most effective tools for caries prevention in clinical practice.

\section{Respiratory diseases and caries Asthma}

Most human clinical studies were undertaken in pediatric cohorts and were case-control in design, aimed at comparing groups with asthma and caries to groups with caries alone. Caries burden was typically measured using DMFT/dmft and DMFS/dmfs indices along with other variables, including microbiological (S. mutans and Lactobacilli counts, oral microbiota assessment using $16 \mathrm{~S}$ sequencing) $[68,69,74]$, medications [70], sugary diet [71], salivary parameters [72, 74] and genetics [18]. Results reinforced previously discovered etiological factors for dental caries in children; namely, consumption of sugary drinks [71], higher S. mutans counts, higher plaque index in caries active children [68], and lower salivary flow rate and $\mathrm{pH}[72,74]$. Other factors related to dental caries activity included tablet delivery of asthma medication [70], the abundance of Veillonella sp. [69] and SNPs of the ameloblastin gene ( $A M B N$ rs4694075) [18].

Heidari et al. explained the association of higher caries burden with asthma to the use of tablet form of asthma medication on grounds that tablet formulation delivers a higher drug dose when compared to syrup and spray forms of medications[70]. It is possible that these patients presented with severe symptoms of asthma and therefore required higher drug dose, but that information was not clearly presented. Other studies have shown an association between inhaled corticosteroids for asthma and higher burden of dental caries [73, 102, 103]. Additionally, while the duration of intake of medication was not associated with severity of caries in this study, there are other studies that found contrary results [68, 104]. Cherkasov et al. found an increased relative abundance of Veillonella from dental biofilm in caries-affected children when compared to caries-free children with asthma [69]. While Veillonella is not considered a cause of dental caries like $S$. mutans, these results are not surprising. Veillonella can metabolize lactate which is produced in abundance by cariogenic streptococci in dental biofilms [105], and various studies have previously demonstrated increased levels of Veillonella in carious lesions [106-110].

Ergöz et al. found an association between $A M B N$ rs4694075 and dental caries in asthmatics, which is an interesting finding. It should be noted that other genome wide association studies (GWAS) studies and GWAS meta-analyses arrived at differing conclusions [111, 112]. Additionally, Ergöz et al. did not mention any dental developmental defects in their cases and so the potential of these being confounding factors may not be applicable. However, it may be argued that since mutations in ameloblastin $(A M B N)$ and other dental development genes are related to dental developmental defects [113], clinical information on absence of dental developmental defects may be considered when evaluating and reporting genetic association of dental development genes and asthma.

While it appears that nature of the association of asthma with dental caries is uncertain, it is prudent to employ prevention strategies for dental caries in asthma patients $[114,115]$.

\section{Cystic fibrosis (CF)}

Two human studies described an association between dental caries and CF $[66,67]$. These studies evaluated caries, molar-incisor hypomineralization, oral hygiene, diet and salivary factors in groups with and without CF. 
Peker et al. noted lower caries experience (DMF-T) in CF patients, and suggested this could be related to frequent use of antibiotics [67]. Salivary factors studied were not significantly different between the groups. Contrary to human clinical studies, a CF mouse model showed significantly higher caries experience and significantly reduced salivary bicarbonate concentration in CF mice [75]. Although human salivary studies of CF did not show significant differences between controls and cases, interest in exploring salivary biochemical composition in CF patients is practical. CF is caused by mutations in the CFTR gene (CF transmembrane conductance regulator) which is a chloride and bicarbonate channel [116] and CFTR mRNA has been localized in the ductal cells of salivary glands [117]. In a mouse model with deletion of phenylalanine 508, significantly increased counts of S.mutans along with increased caries incidence and severity were noted. In the same mouse model, salivary bicarbonate concentration was significantly reduced when compared to wildtype littermates [75]. However, human studies on salivary parameters in CF patients do not consistently show low $\mathrm{pH}$ and higher caries severity and systematic review on this data has shown limitations in study design and high risk of bias [118].

\section{Gastrointestinal diseases and caries}

Limited clinical studies were found assessing a connection between caries and gastrointestinal diseases, including studies of inflammatory gastrointestinal diseases [76-78]. A human clinical study (case-control) showed that pediatric participants with inflammatory bowel disease had significantly more caries and periodontal inflammation than healthy participants [76, 77]. Similar results in an adult cohort has been shown previously [119]. In another study, CD patients who had resective surgery demonstrated a greater caries experience, cariogenic microbiota, oral hygiene and poor diet when compared to controls [78]. In other studies, CD patients have demonstrated increased caries prevalence $[77,119,120]$, increased sugar intake [121, 122] and increased levels of S. mutans [123], one of the bacterial species strongly linked to caries activity. The presence of these factors creates a conducive environment for accelerated caries activity. Patients with IBD have shown increased odds for dental caries in a recent study, confirming previous results in aforementioned studies (4.27 for CD and 2.21 for UC) [77].

Kojima et al. undertook an interesting study using a colitis mouse model to study effects of a serotype of $S$. mutans. Results showed that serotype $k$ of $S$. mutans was able to evade host response in peripheral blood due to variation in glucose surface side chains. Also, uptake of $S$. mutans by hepatocytes, which was potentially facilitated by collagen binding protein, aggravated colitis due to production of IFN- $\gamma$ by liver [79].

S. mutans can be divided into four serotypes $(c, e, f$, $k$ ) and serotypes $f$ and $k$ predominantly carry the $\mathrm{cnm}$ gene. The presence of $\mathrm{cnm}$ gene confers a collagen binding property to specific $S$. mutans serotypes and has been demonstrated to be essential for invasiveness into human coronary artery endothelium [13]. In the study by Kojima et al., significantly more IBD patients showed cnm encoding $S$. mutans (serotype $k$ or $f$ ). Of note, this study showed hepatocyte involvement by $S$. mutans as a crucial step in the colitis mouse model while $S$. mutans was undetectable in samples from the gut [79]. This observation suggests that oral microbiota may affect a disease state in an organ that it does not invade directly by modulating the inflammatory environment. These authors have published follow up studies, investigating the relationship between $S$. mutans serotype $k$ and liver disease in mouse models. These studies showed aggravation of nonalcoholic steatohepatitis by a specific strain of S.mutans through participation of cell surface proteins, including collagen-binding protein $[124,125]$.

\section{Neurologic diseases and caries}

Cardoso et al. studied dental caries burden in patients with cerebral palsy and noted that these patients had high prevalence of dental caries and mean DMFT/dmft values of 1.71 and 2.22 respectively. Further, they found that caregiver awareness and education was associated with dental caries experience in these patients $(\mathrm{PR}=1.439)$ [80]. Control of dental biofilm in patients who are limited in their physical and mental capability is challenging [126, 127] and becomes the collective undertaking of caregiver and dentist and thus, education of the caregiver plays a crucial role in achieving this collective goal [80]. Similarly, enhanced preventive measures can be extended in the geriatric population where compromised motor control and masticatory efficiency results in a shift to a softer diet and that along with exposed root surfaces further increases possibility of dental caries [128, 129].

Delwel et al. raised an important point about composite nature of DMFT index, wherein caries experience (decayed component of DMFT) should be evaluated separately to assess caries burden and for statistical comparison between groups [130]. Overall, standardization in dental indices and utilization of semantics and ontology frameworks should enhance our ability for data analysis and draw robust conclusions.

In a case-control study of participants with ADHD, Paszynska et al. found significantly higher BMI in test group and significantly higher ICDAS 5 and 6 scores (teeth with advanced caries) in the primary dentition. They also found that increased intake of sugary foods and 
drinks were significantly higher in ADHD group[81]. It appears that in studies determining associations of dental caries with neurological and behavioral disorders, standardized interviews for caretakers, food habits and other social determinants will be crucial in order to draw informed conclusions and not extrapolate mechanistic links between systemic diseases and dental caries.

\section{Other diseases and caries}

In our review of literature, we found a few articles that could not be categorized by organ system and/or were not adequate in number to warrant their own section in this review. These diseases included RA, chronic renal diseases and systemic lupus erythematosus.

DMFT/DMFS were associated with RA as assessed by disease activity score and serologic markers. Also, S.mutans was significantly higher in RA patients and indices for oral inflammatory burden and disease were associated with serologic markers for RA. Furthermore, the oral inflammatory burden was significantly higher in early untreated RA when compared to chronic RA [82]. $\mathrm{RA}$ is a risk factor for both caries and periodontal disease [3]. The plausible link between compromised plaque control and joint dysfunction is reasonable but the contribution of RA to overall inflammatory burden is also an important consideration [131]. Active SLE patients showed increased dental caries activity including smooth surface caries when compared to inactive SLE. Furthermore, salivary $\mathrm{pH}$ and flow were significantly reduced and high counts of S.mutans were noted [84]. Another study showed relationship between compromised biofilm control, SLE severity and dental caries [85]. These results raise the possibility of SLE being coincidental in the direct relationship between poor oral hygiene and dental caries. In one study that explored associations between dental caries and chronic kidney disease (CKD), disease group demonstrated significantly higher CFUs of S.mutans and IgA response but significantly lower filled teeth when compared to controls [86]. Importantly, in this study, plaque index was similar between the two groups. Other studies have demonstrated lower dental caries in CKD patients $[132,133]$ and proposed the need for longitudinal studies exploring association between dental caries and CKD.

Although evidence of the association between SLE, RA and dental caries is limited, risk stratification of patients in consultation with rheumatologist may facilitate preventive dental care. Determination of xerostomia in patients with SLE or RA is advised since these patients often have associated Sjögren's syndrome (secondary Sjögren's syndrome) and may experience higher dental caries burden secondary to xerostomia, requiring preventive measures [134]. Sjögren's syndrome is a chronic inflammatory autoimmune disease that usually involves exocrine glands including salivary glands [135]. Additionally, other risk factors such as past caries experience, ability to maintain oral hygiene if limited by joint dysfunction and root exposure commonly noted in elderly patients may help with development of a customized dental caries preventive care plan. Similarly, diet in patients with CKD tend to be carbohydrate rich and that along with poor oral hygiene can increase risk for dental caries [132]. In the caries prevention plan for patients with CKD, oral hygiene should be maintained meticulously through proper home care and periodic dental appointments.

The oral cavity has evolved with a symbiotic and diverse microbiota which serves under some circumstances as a safeguard against numerous environmental challenges [136]. Conditions that disrupt this balance include breach in mucosal defenses and acquisition of pathogenic species, or pathogenic traits by certain commensal microbiota. Examples of acute local infections that occur secondary to breach of mucosal barriers and/or colonization by pathogenic microbiota include dental abscess and lymphadenopathy. Dental caries may also influence a systemic response through direct extension of pertinent microbiota or resulting inflammation. A systemic exposure to effects of caries is also plausible through marginal caries that extends to the periodontium or by pulpal involvement. The systemic influence of dental caries both by direct extension of oral microbiota and creation of a pro-inflammatory state are reasonable hypotheses. However, the obvious challenge is to prove such hypothetical mechanisms by human studies. The chronicity of caries as a disease and the ethical challenges imposed by not treating dental caries are significant challenges for future studies.

We expect that mechanistic explanations of dental caries-systemic disease associations in future studies will likely come from animal models. Also, animal models can inform human studies on variables of interest. In this regard, longitudinal studies that are aimed at evaluating oral and systemic variables of interest in periods of accelerated dental caries in the human host will prove useful. This study is a scoping review and provides an overview of available evidence on the topic of associations between dental caries and systemic diseases. It has a wider scope and does not limit the analysis to one systemic disease. This analysis is not as rigorous as that offered by systematic reviews and meta-analyses and the information presented should be used in complement to systematic reviews and meta-analyses on this topic. 


\section{Conclusions}

Limited clinical evidence was found connecting several systemic diseases and dental caries. When adequate clinical results were available, it offered mixed evidence of such associations. Interesting animal studies were noted that could generate clinical hypotheses and further investigations in rodent models for cardiovascular injury and hyperglycemia. Best evidence from human and animal studies described the association between metabolic diseases and dental caries. Animal studies using rodent models demonstrated significant changes in dental tissues following hyperglycemia. Also, an association between hyperglycemia and dental caries was consistently noted in animal studies. Inadequate data was found to suggest any modifications to current clinical practice or prevention guidelines.

\section{Abbreviations}

AD: Alzheimer Disease; ADHD: Attention Deficit Hyperactivity Disorder; BEWE: Basic Erosive Wear Examination; BMI: Body Mass Index; CAMBRA: Caries Management by Risk Assessment; CKD: Chronic Kidney Disease; CFU: Colony Forming Unit; CPITN: Community Periodontal Index of Treatment Needs; CAD: Coronary Artery Disease; CRP: C-Reactive Protein; CD: Crohn's Disease; CF: Cystic Fibrosis; CFTR: Cystic Fibrosis Transmembrane Conductance Regulator; DI: Debris Index; DT: Decayed Teeth; DFSa: Decayed, and Filled Approximal Surfaces; DEFS: Decayed, Extracted, and Filled Surfaces; DMFS/dmfs: Decayed, Missing, and Filled Surfaces; DMFT/dmft: Decayed, missing, and Filled Teeth; DSS: Dextran Sodium Sulfate;T1DM: Diabetes Mellitus Type I;T2DM: Diabetes Mellitus Type II; FT: Filled Teeth; GWAS: Genome Wide Association Studies; GUDC: Grade of Severity of Untreated Dental Caries; HDL: High Density Lipoprotein; IBD: Inflammatory Bowel Disease; ICDAS: International Caries Detection and Assessment System; IOTF: International Obesity Task Force; MeSH: Medical Subject Heading; MetS: Metabolic Syndrome; MT: Missing Teeth; $\mathrm{MIH}$ : Molar-Incisor Hypomineralization; OR: Odds Ratio; OHI-S: Oral Hygiene Index-Simplified; PHP-M: Personal Hygiene Performance-Modified Index; PI: Plaque Index; RA: Rheumatoid Arthritis; S-ECC: Severe Early Childhood Caries; SiC: Significant Caries Index; SLE: Systemic Lupus Erythematosus; TLR: Toll-like Receptor; TDI: Total Dental Index; UC: Ulcerative Colitis; WHO: World Health Organization.

\section{Acknowledgements}

Not applicable.

\section{Authors' contributions}

All authors have read and approved the manuscript. AS and FAS reviewed and compiled evidence and wrote the manuscript. ES formulated the search strategy, compiled evidence and reviewed the manuscript. All authors read and approved the final manuscript.

\section{Funding}

No funding was obtained for this study.

\section{Availability of data and materials}

Not applicable.

\section{Declarations}

Ethics approval and consent to participate No ethics approval and consent to participate was required for this manuscript.

\section{Consent for publication}

No consent for publication was required for this manuscript.

\section{Competing interests}

The authors do not have any financial and non-financial competing interests to declare for this manuscript.

\section{Author details}

${ }^{1}$ Division of Periodontics, Schulich School of Medicine and Dentistry, DSB 0156A, Western University, 1151 Richmond St., London, ON N6A 5C1, Canada. ${ }^{2}$ Department of Periodontics and Endodontics, School of Dental Medicine, University at Buffalo, 3435 Main St., Buffalo, NY 14214, USA. ${ }^{3}$ Health Sciences Library University at Buffalo, 3435 Main St., Buffalo, NY 14214, USA. ${ }^{4}$ Department of Oral Biology, School of Dental Medicine, University at Buffalo, 3435 Main St, Buffalo, NY 14214, USA.

Received: 27 December 2020 Accepted: 1 September 2021

Published online: 25 September 2021

\section{References}

1. Marcenes W, Kassebaum NJ, Bernabé E, Flaxman A, Naghavi M, Lopez A Murray CJ. Global burden of oral conditions in 1990-2010: a systematic analysis. J Dent Res. 2013;92(7):592-7.

2. Vos T, Flaxman AD, Naghavi M, Lozano R, Michaud C, Ezzati M, Shibuya K, Salomon JA, Abdalla S. Aboyans V: Years lived with disability (YLDs) for 1160 sequelae of 289 diseases and injuries 1990-2010: a systematic analysis for the Global Burden of Disease Study 2010. The Lancet. 2012;380(9859):2163-96.

3. Chapple IL, Bouchard P, Cagetti MG, Campus G, Carra MC, Cocco F, Nibali L, Hujoel P, Laine ML, Lingström P, Manton DJ. Interaction of lifestyle, behaviour or systemic diseases with dental caries and periodontal diseases: consensus report of group 2 of the joint EFP/ORCA workshop on the boundaries between caries and periodontal diseases. J Clin Periodontol. 2017:44:S39-51.

4. Glick M. The oral-systemic health connection: a guide to patient care. Incorporated: Quintessence Publishing Company; 2014.

5. Henderson B, Curtis M, Seymour R, Donos N. Periodontal medicine and systems biology. Hoboken: John Wiley \& Sons; 2009.

6. Rose LF, Genco RJ, Cohen DW, Mealey BL: Periodontal medicine. BC Decker Hamilton, ON and London 2000.

7. Kubota M, Yanagita M, Mori K, Hasegawa S, Yamashita M, Yamada S, Kitamura M, Murakami S. The effects of cigarette smoke condensate and nicotine on periodontal tissue in a periodontitis model mouse. Plos one. 2016;11(5).

8. Sugiyama S, Takahashi S-S, Tokutomi F-a, Yoshida A, Kobayashi K, Yoshino F, Wada-Takahashi S, Toyama T, Watanabe K, Hamada $\mathrm{N}$, et al: Gingival vascular functions are altered in type 2 diabetes mellitus model and/or periodontitis model. J Clin Biochem Nutr. 2011;1203270147

9. Pitts NB, Zero DT, Marsh PD, Ekstrand K, Weintraub JA, Ramos-Gomez F, Tagami J, Twetman S, Tsakos G, Ismail A. Dental Caries. 2017;3(1):1-16.

10. Scannapieco FA. The oral microbiome: its role in health and in oral and systemic infections. Clin Microbiol Newslett. 2013;35(20):163-9.

11. Pedersen AML, Bardow A, Nauntofte B. Salivary changes and dental caries as potential oral markers of autoimmune salivary gland dysfunction in primary Sjögren's syndrome. BMC Clin Pathol. 2005;5(1):1-13.

12. Hu K-F, Chou Y-H, Wen Y-H, Hsieh K-P, Tsai J-H, Yang P, Yang Y-H, Lin C-HR. Antipsychotic medications and dental caries in newly diagnosed schizophrenia: a nationwide cohort study. Psychiatry Res. 2016;245:45-50.

13. Abranches J, Miller JH, Martinez AR, Simpson-Haidaris PJ, Burne RA, Lemos JA. The collagen-binding protein $\mathrm{Cnm}$ is required for Streptococcus mutans adherence to and intracellular invasion of human coronary artery endothelial cells. Infect Immunity. 2011;79(6):2277-2284.

14. Lemos J, Palmer S, Zeng L, Wen Z, Kajfasz J, Freires I, Abranches J, Brady L. The biology of Streptococcus mutans. Microbiol Spectrum. 2019;7(1):7.1.03.

15. Nomura R, Otsugu M, Hamada M, Matayoshi S, Teramoto N, Iwashita N, Naka S, Matsumoto-Nakano M, Nakano K. Potential involvement of Streptococcus mutans possessing collagen binding protein $\mathrm{Cnm}$ in infective endocarditis. Sci Rep. 2020;10(1):1-14. 
16. Tanner A, Kressirer C, Rothmiller S, Johansson I Chalmers N. The caries microbiome: implications for reversing dysbiosis. Adv Dent Res. 2018:29(1):78-85.

17. Valm AM. The structure of dental plaque microbial communities in the transition from health to dental caries and periodontal disease. J Mol Biol. 2019;431(16):2957-69.

18. Ergöz N, Seymen F, Gencay K, Tamay Z, Deeley K, Vinski S, Vieira A. Genetic variation in Ameloblastin is associated with caries in asthmatic children. Eur Arch Paediatr Dentist. 2014;15(3):211-16.

19. Chi DL, Luu M, Chu F. A scoping review of epidemiologic risk factors for pediatric obesity: implications for future childhood obesity and dental caries prevention research. J Public Health Dent. 2017;77:8-31.

20. Abbassy M, Watari I, Bakry A, Hamba H, Hassan AH, Tagami J. Ono T. Diabetes detrimental effects on enamel and dentine formation. J Dentist. 2015, 43(5):589-96.

21. Claudino M, Nunes IS, Gennaro G, Cestari TM, Spadella CT, Garlet GP de Assis GF. Diabetes triggers the loss of tooth structure associated to radiographical and histological dental changes and its evolution to progressive pulp and periapical lesions in rats. Arch Oral Biol. 2015:60(11):1690-8

22. Nakahara Y, Ozaki K, Matsuura T. Long-term hyperglycemia naturally induces dental caries but not periodontal disease in type 1 and type 2 diabetic rodents. Diabetes. 2017;66(11):2868-74

23. Nakahara Y, Sano T, Kodama Y, Ozaki K, Matsuura T. Alloxan-induced hyperglycemia causesrapid-onset and progressive dental caries and periodontitis in F344 rats. Histol Histopathol 2012;27(10):1297-306. https://doi.org/10.14670/HH-27.1297.

24. Nakahara Y, Sano T, Kodama Y, Ozaki K, Matsuura T. Glycemic control with insulin prevents progression of dental caries and cariesrelated periodontitis in diabetic WBN/KobSlc rats. Toxicol Pathol. 2013:41(5):761-9.

25. Nishimoto T, Kodama Y, Matsuura T, Ozaki K, Taniguchi Y. Hyperglycemia simultaneously induces initial caries development and enhances spontaneous occlusal surface wear in molar teeth related to parotid gland disorder in alloxan-induced diabetic rats. J Toxicol Pathol. 2017:30(1):47-55.

26. Sano T, Matsuura T, Ozaki K, Narama I. Dental caries and caries-related periodontitis in type 2 diabetic mice. Vet Pathol. 2011:48(2):506-12.

27. Yeh C-K, Harris SE, Mohan S, Horn D, Fajardo R, Chun Y-HP, Jorgensen J, MacDougall M. Abboud-Werner S. Hyperglycemia and xerostomia are key determinants of tooth decay in type 1 diabetic mice. Lab Investig. 2012;92(6):868-882

28. Arksey H, O'Malley, L. Scoping studies: towards a methodological framework. Int J Soc Res Methodol. 2005;8(1):19-32.

29. Fadel HT, Al-Kindy KA, Mosalli M, Heijl L, Birkhed D. Caries risk and periodontitis in patients with coronary artery disease. J Periodontol. 2011;82(9):1295-1303.

30. Siahi-Benlarbi R, Nies SM, Sziegoleit A, Bauer J, Schranz D. Wetzel WE. Caries-, Candida-and Candida antigen/antibody frequency in children after heart transplantation and children with congenital heart disease. Pediatr Transplant. 2010;14(6):715-21.

31. Soto-Barreras U, Olvera-Rubio JO, Loyola-Rodriguez JP, Reyes-Macias JF, Martinez-Martinez RE, Patiño-Marin N, Martinez-Castañon GA, AradillasGarcia C. Little JW. Peripheral arterial disease associated with caries and periodontal disease. J Periodontol. 2013;84(4):486-94.

32. Ostalska-Nowicka D, Paszyńska E, Dmitrzak-Węglarz M, NeymanBartkowiak A, Rabiega A, Zachwieja J, Nowicki M. Dental caries-related primary hypertension in children and adolescents: cross-sectional study. Oral Dis. 2020. https://doi.org/10.1111/odi.13700.

33. Kesavalu L, Lucas A, Verma R, Liu L, Dai E, Sampson E. Progulske-Fox A. Increased atherogenesis during Streptococcus mutans infection in ApoE-null mice. J Dent Res. 2012;91(3):255-260.

34. Hegde MN, Tahiliani D, Shetty S, Devadiga D. Salivary alkaline phosphatase and calcium in caries-active type II diabetes mellitus patients: an in vivo study. Contemp Clin Dentis. 2014;5(4):440.

35. Lai S, Cagetti MG, Cocco F, Cossellu D, Meloni G, Campus G, Lingström $P$. Evaluation of the difference in caries experience in diabetic and non-diabetic children-A case control study. PloS one. 2017;12(11):e0188451.

36. Majbauddin A, Tanimura C, Aoto H, Otani S, Parrenas MC, Kobayashi $\mathrm{N}$, Morita T, Inoue K, Masumoto T, Kurozawa Y. Association between dental caries indicators and serum glycated hemoglobin-levels among patients with type 2 diabetes mellitus. Journal of oral science. 2019;61(2):335-42.

37. Singh-Hüsgen $P$, Meissner T, Bizhang M, Henrich $B$, Raab WH. Investigation of the oral status and microorganisms in children with phenylketonuria and type 1 diabetes. Clin Oral Investig. 2016;20(4):841-7.

38. Al-Badr AH, AlJameel AH, Halawany HS, Al-Jazairy YH, Alhadlaq MK, AlMaflehi NS, Al-Sharif JA, Jacob V, Abraham N. Dental caries prevalence among Type 1 diabetes mellitus (T1DM) 6-to 12-year-old children in Riyadh, Kingdom of Saudi Arabia compared to non-diabetic children. Saudi Dent J. 2021;33(5):276-82.

39. Kamran S, Moradian H, Bakhsh EY. Comparison of the Mean DMF Index in Type I Diabetic and Healthy Children. J Dent. 2019;20(1):61.

40. Pachoński M, Jarosz-Chobot P, Koczor-Rozmus A, Łanowy P, MocnyPachońska K. Dental caries and periodontal status in children with type 1 diabetes mellitus. Pediatr Endocrinol Diabetes Metab. 2020;26(1).

41. Schmolinsky J, Kocher T, Rathmann W, Völzke H, Pink C, Holtfreter B. Diabetes status affects long-term changes in coronal caries-The SHIP Study. Sci Rep. 2019;9(1):1-11.

42. Alm A, Isaksson H, Fahraeus C, Koch G, Andersson-Gare B, Nilsson M, Birkhed D. Wendt L-K. BMI status in Swedish children and young adults in relation to caries prevalence. Swed Dent. 2011;35(1):1-8.

43. Basha S, Mohamed RN, Swamy HS, Ramamurthy PH, Sexena V. Caries incidence among obese adolescents: a 3-year prospective study. Oral Health Prev Dent. 2017;15(1):65-71.

44. Chala S, El Aidouni M, Abouqal R, Abdallaoui F. U-shaped association between untreated caries and body mass index in adults at Rabat dental University hospital, Morocco: cross sectional study. BMC research notes. 2017;10(1):1-6.

45. Costacurta M, DiRenzo L, Sicuro L, Gratteri S, De Lorenzo A, Docimo R. Dental caries and childhood obesity: analysis of food intakes, lifestyle. Eur J Paediatr Dent. 2014;15(4):343-8.

46. Goodson JM, Tavares M, Wang X, Niederman R, Cugini M, Hasturk H, Barake R, Alsmadi O, Al-Mutawa S, Ariga J, Soparkar P. Obesity and dental decay: inference on the role of dietary sugar. PloS one. 2013;8(10).

47. Hall-Scullin EP, Whitehead H, Rushton H, Milsom K, Tickle M. A longitudinal study of the relationship between dental caries and obesity in late childhood and adolescence. J Public Health Dent. 2018:78(2):100-8.

48. Li LW, Wong HM, McGrath CP. Longitudinal association between obesity and dental caries in adolescents. J Pediatr. 2017;189:149-54.

49. Modéer T, Blomberg CC, Wondimu B, Julihn A, Marcus C. Association between obesity, flow rate of whole saliva, and dental caries in adolescents. Obesity. 2010;18(12):2367-73.

50. Peng SM, Wong HM, King NM, McGrath C. Association between dental caries and adiposity status (general, central, and peripheral adiposity) in 12-year-old children. Caries Res. 2014;48(1):32-8.

51. Sánchez-Pérez L, Irigoyen M, Zepeda M. Dental caries, tooth eruption timing and obesity: a longitudinal study in a group of Mexican schoolchildren. Acta Odontologica Scandinavica. 2010;68(1):57-64.

52. Akarsu S, Karademir SA. Association between body mass index and dental caries in a Turkish subpopulation of adults: A cross-sectional study. Oral Health Prev Dent. 2020;18:85-9.

53. Fraiz GM, Crispim SP, Montes GR, Gil GS, Morikava FS, Bonotto DV, Ferreira FM, Fraiz FC. Excess body weight, snack limits and dental caries in Brazilian preschoolers: A population-based study. Pesquisa Brasileira em Odontopediatria e Clínica Integrada 2019;19.

54. Frias-Bulhosa J, Barbosa P, Gomes E, Vieira MR, Manso MC. Association between body mass index and caries among 13-year-old population in Castelo de Paiva, Portugal. Revista Portuguesa de Estomatologia Medicina Dentária e Cirurgia Maxilofacial. 2015;56(1):3-8.

55. Guaré RO, Perez MM, Novaes TF, Ciamponi AL, Gorjão R, Diniz MB. Overweight/obese children are associated with lower caries experience than normal-weight children/adolescents. Int J Paediatr Dentist. 2019;29(6):756-64.

56. Karki S, Päkkilä J, Ryhänen T, Laitala ML, Humagain M, Ojaniemi M, Anttonen V. Body mass index and dental caries experience in Nepalese schoolchildren. Commun Dent Oral Epidemiol. 2019;47(4):346-57.

57. Kennedy T, Rodd C, Daymont C, Grant CG, Mittermuller BA, Pierce A, Moffatt ME, Schroth RJ. The association of body mass index and severe early childhood caries in young children in Winnipeg, Manitoba: A 
cross-sectional study. International journal of paediatric dentistry. 2020;30(5):626-33.

58. Lock NC, Susin C, Brusius CD, Maltz M, Alves LS. Obesity and dental caries among South Brazilian schoolchildren: a 2.5-year longitudinal study. Braz Oral Res. 2019;33:e056. https://doi.org/10.1590/1807-3107b or-2019.vol33.0056.

59. Serrano-Piña R, Aguilar-Ayala FJ, Scougall-Vilchis RJ, Trujillo-Güiza ML, Mendieta-Zerón H. Prevalence of obesity in elementary school children and its association with dental caries. Oral Health Prev Dentist. 2020;18(1):35-42. https://doi.org/10.3290/j.ohpd.a43366.

60. Sharma B, Indushekar K, Saraf BG, Sardana D, Sheoran N, Mavi S. Are dental caries and overweight/obesity interrelated? A cross-sectional study in rural and urban preschool children. J Indian Soc Pedodontics Prev Dent. 2019;37(3):224.

61. Shen A, Bernabé E, Sabbah W. Severe dental caries is associated with incidence of thinness and overweight among preschool Chinese children. Acta Odontol Scand. 2020;78(3):203-9.

62. Swaminathan K, Anandan V, HS, Thomas E. Correlation between body mass index and dentalcaries among three- to 12-year-old schoolchildren in India: a cross-sectional study. Cureus. 2019;11(8):e5421. https:// doi.org/10.7759/cureus.5421.

63. Tschammler C, Simon A, Brockmann K, Röbl M, Wiegand A. Erosive tooth wear and caries experience in children and adolescents with obesity. J Dent. 2019;83:77-86.

64. Iwasaki T, Hirose A, Azuma T, Ohashi T, Watanabe K, Obora A, Deguchi F, Kojima T, Isozaki A, Tomofuji T. Associations between caries experience, dietary habits, and metabolic syndrome in Japanese adults. J Oral Sci. 2019;61(2):300-6.

65. Adachi N, Kobayashi Y. One-year follow-up study on associations between dental caries, periodontitis, and metabolic syndrome. J Oral Sci. 2020;62(1):52-6.

66. Alkhateeb AA, Mancl LA, Presland RB, Rothen ML, Chi DL. Unstimulated saliva-related caries risk factors in individuals with cystic fibrosis: A cross-sectional analysis of unstimulated salivary flow, pH, and buffering capacity. Caries Res. 2017;51(1):1-6.

67. Peker S, Mete S, Gokdemir Y, Karadag B, Kargul B. Related factors of dental caries and molar incisor hypomineralisation in a group of children with cystic fibrosis. Eur Arch Paediatric Dent. 2014;15(4):275-80.

68. Botelho MP, Maciel SM, Neto AC, Dezan CC, Fernandes KB, De Andrade FB. Cariogenic microorganisms and oral conditions in asthmatic children. Caries Res. 2011;45(4):386-92.

69. Cherkasov SV, Popova LY, Vivtanenko TV, Demina RR, Khlopko YA, Balkin AS, Plotnikov AO. Oral microbiomes in children with asthma and dental caries. Oral Dis. 2019;25(3):898-910.

70. Heidari A, Seraj B, Shahrabi M, Maghsoodi H, Kharazifard MJ, Zarabian T. Relationship between different types and forms of anti-asthmatic medications and dental caries in three to 12 year olds. J Dent. 2016;13(4):238.

71. Stensson M, WENDT LK, Koch G, Nilsson M, Oldaeus G, Birkhed D. Oral health in pre-school children with asthma-followed from 3 to 6 years. Int J Paediatr Dent. 2010;20(3):165-72.

72. Stensson M, Wendt L-K, Koch G, Oldaeus G, Lingström P, Birkhed D. Caries prevalence, caries-related factors and plaque $\mathrm{pH}$ in adolescents with long-term asthma. Caries research. 2010;44(6):540-6.

73. Hassanpour K, Tehrani H, Goudarzian M, Beihaghi S, Ebrahimi M, Amiri P. Comparison of the frequency of dental caries in asthmatic children under treatment with inhaled corticosteroids and healthy children in Sabzevar in 2017-2018. Electron J Gen Med. 2019;16(2):6.

74. Khalifa MAAA, Abouelkheir HM, Khodiar SE-F, Mohamed GAM. Salivary composition and dental caries among children controlled asthmatics. Egyptian Journal of Chest Diseases Tuberculosis. 2014;63(4):777-88.

75. Catalán MA, Scott-Anne K, Klein MI, Koo H, Bowen WH, Melvin JE. Elevated incidence of dental caries in a mouse model of cystic fibrosis. PloS one. 2011;6(1).

76. Koutsochristou V, Zellos A, Dimakou K, Panayotou I, Siahanidou S, Roma-Giannikou E, Tsami A. Dental caries and periodontal disease in children and adolescents with inflammatory bowel disease: a casecontrol study. Inflam Bowel Dis. 2015;21 (8):1839-46.

77. Zhang L, Gao X, Zhou J, Chen S, Zhang J, Zhang Y, Chen B, Yang $J$. Increased risks of dental caries and periodontal disease in Chinese patients with inflammatory bowel disease. Int Dent J. 2020:70(3):227-36.
78. Szymanska S, Lördal M, Rathnayake N, Gustafsson A, Johannsen A. Dental caries, prevalence and risk factors in patients with Crohn's disease. PLoS One. 2014;9(3).

79. Kojima A, Nakano K, Wada K, Takahashi H, Katayama K, Yoneda M, Higurashi T, Nomura R, Hokamura K, Muranaka Y, Matsuhashi N. Infection of specific strains of Streptococcus mutans, oral bacteria, confers a risk of ulcerative colitis. Sci Rep. 2012;2(1):1-11.

80. Cardoso AM, Gomes LN, Silva CRD, Soares RDS, De Abreu MHN, Padilha WW, Cavalcanti AL. Dental caries and periodontal disease in Brazilian children and adolescents with cerebral palsy. Int J Environ Res Public Health. 2015;12(1):335-53.

81. Paszynska E, Dmitrzak-Węglarz M, Perczak A, Gawriolek M, Hanć T, Bryl E, Mamrot P, Dutkiewicz A, Roszak M, Tyszkiewicz-Nwafor M. Excessive weight gain and dental caries experience among children affected by ADHD. International Journal of Environmental Research Public Health. 2020;17(16):5870.

82. Äyräväinen L, Heikkinen AM, Kuuliala A, Ahola K, Koivuniemi R, Peltola J, Suomalainen A, Moilanen E, Hämäläinen M, Laasonen L, Meurman $\mathrm{JH}$. Activity of rheumatoid arthritis correlates with oral inflammatory burden. Rheumatol Int. 2018;38(9):1661-9.

83. Martinez-Martinez RE, Domínguez-Pérez RA, Sancho-Mata J, AbudMendoza C, Ayala-Herrera JL, Popoca-Hernandez EA. The frequency and severity of dental caries, and counts of cariogenic bacteria in rheumatoid arthritis patients. Dent Med Probl. 2019;56(2):137-42.

84. Loyola Rodriguez JP, Galvan Torres LJ, Martinez Martinez RE, Abud Mendoza C, Medina Solis CE, Ramos Coronel S, Garcia Cortes JO, Domínguez Pérez RA. Frequency of dental caries in active and inactive systemic lupus erythematous patients: salivary and bacterial factors. Lupus. 2016;25(12):1349-56.

85. Gofur NRP, Handono K, Nurdiana N, Kalim H, Barlianto W. Oral hygiene and dental caries status on systemic lupus erythematosus patients: a cross-sectional study. Pesqui Bras Odontopediatria Clín Integr. 2020;20:e0013. https://doi.org/10.1590/pboci.2020.116.

86. Menezes CR, Pereira AL, Ribeiro CC, Chaves CO, Guerra RN, Thomaz ÉB, Monteiro-Neto V, Alves CM. Is there association between chronic kidney disease and dental caries? A case-controlled study. Medicina oral, patologia oral y cirugia bucal. 2019;24(2):e211.

87. Da Silva DB, Souza IP, Cunha MC. Knowledge, attitudes and status of oral health in children at risk for infective endocarditis. Int J Paediatr Dent. 2002;12(2):124-31.

88. Grahn K, Wikström S, Nyman L, Rydberg A, STECKSÉN-BLICKS C. Attitudes about dental care among parents whose children suffer from severe congenital heart disease: a case-control study. Int J Paediatr Dent. 2006;16(4):231-8.

89. Rosén L, Stecksen-Blicks C. Experience of dental care for children with congenital heart disease among Swedish dentists. Swedish Dent J. 2007;31(2):85-90

90. Suvarna R, Rai K, Hegde AM. Knowledge and oral health attitudes among parents of children with congenital heart disease. Int J Clin Pediatr Dent. 2011;4(1):25.

91. Abranches J, Zeng L, Belanger M, Rodrigues PH, Simpson-Haidaris PJ, Akin D, Dunn WA Jr, Progulske-Fox A, Burne RA. Invasion of human coronary artery endothelial cells by Streptococcus mutans OMZ175. Oral microbiol Immunol. 2009;24(2):141-5.

92. Selekman, R. E., Shapiro, D. J., Boscardin, J., Williams, G., Craig, J. C., Brandström, P., Pennesi, M., Roussey-Kesler, G., Hari, P., \& Copp, H. L. (2018). Uropathogen resistance and antibiotic prophylaxis: a metaanalysis.Pediatrics 142(1):e20180119. https://doi.org/10.1542/peds. 2018-0119.

93. Wilson W, Taubert KA, Gewitz M, Lockhart PB, Baddour LM, Levison M, Bolger A, Cabell CH, Takahashi M, Baltimore RS. Prevention of infective endocarditis: guidelines from the American heart association: a guideline from the American heart association rheumatic fever, endocarditis, and Kawasaki disease committee, council on cardiovascular disease in the young, and the council on clinical cardiology, council on cardiovascular surgery and anesthesia, and the quality of care and outcomes research interdisciplinary working group. Circulation. 2007:116(15):1736-54

94. Li J, Zhao F, Wang Y, Chen J, Tao J, Tian G, Wu S, Liu W, Cui Q, Geng B. Gut microbiota dysbiosis contributes to the development of hypertension. Microbiome. 2017;5(1):1-19. 
95. Bryan NS, Tribble G, Angelov N. Oral microbiome and nitric oxide: the missing link in the management of blood pressure. Curr Hypertens Rep. 2017;19(4):1-8

96. Vallianou NG, Geladari E, Kounatidis D. Microbiome and hypertension: where are we now? J Cardiovasc Med. 2020;21(2):83-8.

97. Commodore-Mensah Y, Turkson-Ocran R-A, Foti K, Cooper LA, Himmelfarb CD. Associations between social determinants and hypertension, stage 2 hypertension, and controlled blood pressure among men and women in the United States. Am J Hypertens. 2021.

98. Monse B, Duijster D, Sheiham A, Grijalva-Eternod CS, van Palenstein Helderman W, Hobdell MH. The effects of extraction of pulpally involved primary teeth on weight, height and BMI in underweight Filipino children. A cluster randomized clinical trial. BMC Public Health. 2012;12(1):1-7.

99. Selwitz RH, Ismail Al, Pitts NB. Dental caries. 2007;369(9555):51-59.

100. Chen D, Zhi Q, Zhou Y, Tao Y, Wu L, Lin H. Association between dental caries and BMI in children: a systematic review and meta-analysis. Caries Res. 2018;52(3):230-45

101. Tellez M, Gomez J, Pretty I, Ellwood R, Ismail Al. Evidence on existing caries risk assessment systems: are they predictive of future caries? Community Dent Oral Epidemiol. 2013;41(1):67-78.

102. Kargul B, Tanboga I, Ergeneli S, Karakoc F, Dagli E. Inhaler medicament effects on saliva and plaque $\mathrm{pH}$ in asthmatic children. J Clin Pediatr Dent. 1998:22(2):137-40.

103. Santos NC, Jamelli S, Costa L, Baracho Filho C, Medeiros D, Rizzo JA, Sarinho E. Assessing caries, dental plaque and salivary flow in asthmatic adolescents using inhaled corticosteroids. Allergologia et immunopathologia. 2012;40(4):220-4.

104. Eloot AK, Vanobbergen JN, De Baets F, Martens LC. Oral health and habits in children with asthma related to severity and duration of condition. Eur J Paediatr Dent. 2004;5(4):210-5.

105. Ng SK, Hamilton IR. Lactate metabolism by Veillonella parvula. J Bacteriol. 1971:105(3):999-1005.

106. Aas JA, Griffen AL, Dardis SR, Lee AM, Olsen I, Dewhirst FE, Leys EJ, Paster BJ. Bacteria of dental caries in primary and permanent teeth in children and young adults. J Clin Microbiol. 2008;46(4):1407-17.

107. Becker MR, Paster BJ, Leys EJ, Moeschberger ML, Kenyon SG, Galvin $J$, Boches SK, Dewhirst FE, Griffen AL. Molecular analysis of bac terial species associated with childhood caries. J Clin Microbiol. 2002:40(3):1001-9.

108. Gross EL, Beall CJ, Kutsch SR, Firestone ND, Leys EJ. Griffen AL. Beyond Streptococcus mutans: dental caries onset linked to multiple species by 16S rRNA community analysis. 2012;7(10):e47722.

109. Lima KC, Coelho LT, Pinheiro IV, Rocas IN, Siqueira JF Jr. Microbiota of dentinal caries as assessed by reverse-capture checkerboard analysis. Caries Res. 2011:45(1):21-30.

110. Tanner AC, Mathney JM, Kent RL, Chalmers NI, Hughes CV, Loo CY, Pradhan N, Kanasi E, Hwang J, Dahlan MA, Papadopolou E. Cultivable anaerobic microbiota of severe early childhood caries. J Clin Microbiol. 2011;49(4):1464-74

111. Demenais F, Margaritte-Jeannin P, Barnes KC, Cookson WO, Altmüller J, Ang W, Barr RG, Beaty TH, Becker AB. Beilby JJNg: Multiancestry association study identifies new asthma risk loci that colocalize with immunecell enhancer marks. Nat Genet. 2018;50(1):42-53.

112. Kim KW, Ober C. Lessons learned from GWAS of asthma. Allergy Asthma Immunol Res. 2019;11(2):170-87.

113. Jeremias F, Koruyucu M, Küchler EC, Bayram M, Tuna EB, Deeley K, Pierri RA, Souza JF, Fragelli CM, Paschoal MA, Gencay K. Genes expressed in dental enamel development are associated with molar-incisor hypomineralization. Arch Oral Biol. 2013;58(10):1434-42.

114. Agostini BA, Collares KF, Costa FdS, Correa MB, Demarco FF. The role of asthma in caries occurrence-meta-analysis and meta-regression. J Asthma. 2019;56(8):841-52.

115. Matthews J. Asthma and dental caries. 2012;13(2):41.

116. Kunzelmann K, Schreiber R, Hadorn HB. Bicarbonate in cystic fibrosis. J Cystic Fibrosis. 2017;16(6):653-62.

117. Trezíse AE, Buchwald M. In vivo cell-specific expression of the cystic fibrosis transmembrane conductance regulator. Nature. 1991;353(6343):434-437.
118. Chi DL. Dental caries prevalence in children and adolescents with cystic fibrosis: a qualitative systematic review and recommendations for future research. Int J Paediatr Dentist. 2013;23(5):376-386.

119. Brito F, Barros FC, Zaltman C, Pugas Carvalho AT, de Vasconcellos Carneiro AJ, Fischer RG, Gustafsson A, de Silva Figueredo CM. Prevalence of periodontitis and DMFT index in patients with Crohn's disease and ulcerative colitis. J Clin Periodontol. 2008;35(6):555-60.

120. SchützT, Drude C, Paulisch E, Lange KP, Lochs H. Sugar intake, taste changes and dental health in Crohn's disease. Dig Dis. 2003;21(3):252-7.

121. Sakamoto N, Kono S, Wakai K, Fukuda Y, Satomi M, Shimoyama T, Inaba Y, Miyake Y, Sasaki S, Okamoto K, Kobashi G. Dietary risk factors for inflammatory bowel disease A Multicenter Case-Control Study in Japan. Inflam Bowel Dis. 2005;11(2):154-63.

122. Tragnone A, Valpiani D, Miglio F, Elmi G, Bazzocchi G, Pipitone E, Lanfranchi GA. Dietary habits as risk factors for inflammatory bowel disease. Eur J Gastroenterol Hepatol. 1995;7(1):47-51.

123. Sundh B, Emilson C-G. Salivary and microbial conditions and dental health in patients with Crohn's disease: a 3-year study. Oral Surg Oral Med Oral Pathol. 1989;67(3):286-90.

124. Naka S, Hatakeyama R, Takashima Y, Matsumoto-Nakano M, Nomura R, Nakano K. Contributions of Streptococcus mutans Cnm and PA antigens to aggravation of non-alcoholic steatohepatitis in mice. Sci Rep. 2016;6:36886

125. Naka S, Nomura R, Takashima Y, Okawa R, Ooshima T, Nakano K. A specific Streptococcus mutans strain aggravates non-alcoholic fatty liver disease. Oral Dis. 2014:20(7):700-6.

126. Jablonski RA, Therrien B, Mahoney EK, Kolanowski A, Gabello M, Brock $A$. An intervention to reduce care-resistant behavior in persons with dementia during oral hygiene: a pilot study. Spec Care Dent. 2011;31(3):77-87.

127. Naorungroj S, Slade G, Beck J, Mosley T, Gottesman RF, Alonso A, Heiss G. Cognitive decline and oral health in middle-aged adults in the ARIC study. J Dent Res. 2013;92(9):795-801.

128. Elsig F, Schimmel M, Duvernay E, Giannelli SV, Graf CE, Carlier S, Herrmann FR, Michel JP, Gold G, Zekry D. Tooth loss, chewing efficiency and cognitive impairment in geriatric patients. Geodontology. 2015:32(2):149-56.

129. Weijenberg RA, Lobbezoo F, Visscher CM, Scherder EJ. Oral mixing ability and cognition in elderly persons with dementia: a cross-sectional study. J Oral Rehabil. 2015:42(7):481-6.

130. Delwel S, Binnekade TT, Perez RS, Hertogh CM, Scherder EJ, Lobbezoo F. Oral health and orofacial pain in older people with dementia: a systematic review with focus on dental hard tissues. Clin Oral Investig. 2017:21(1):17-32.

131. Hashimoto H, Hashimoto S, Muto A, Dewake N, Shimazaki Y. Influence of plaque control on the relationship between rheumatoid arthritis and periodontal health status among Japanese rheumatoid arthritis patients. J Periodontol. 2018;89(9):1033-42.

132. Andrade MRTC, Antunes LAA, de Araujo Soares RM, Leão ATT, Primo Maia LC., L,. Lower dental caries prevalence associated to chronic kidney disease: a systematic review. Pediatr Nephrol. 2014;29(5):771-8.

133. Tadakamadla J, Kumar S, Mamatha GP. Comparative evaluation of oral health status of chronic kidney disease (CKD) patients in various stages and healthy controls. Spec Care Dent. 2014;34(3):122-6.

134. Zero DT, Brennan MT, Daniels TE, Papas A, Stewart C, Pinto A, Al-Hashimi I, Navazesh M, Rhodus N, Sciubba J. Clinical practice guidelines for oral management of Sjögren disease: dental caries prevention. J Am Dent Assoc. 2016;147(4):295-305.

135. Vitali C, Bombardieri S, Jonsson R, Moutsopoulos H, Alexander E, Carsons S, Daniels T, Fox P, Fox R, Kassan S. European Study Group on Classification Criteria for Sjögren's Syndrome. Classification criteria for Sjögren's syndrome: a revised version of the European criteria proposed by the American-European Consensus Group. 2002.

136. van der Meulen TA, Harmsen HJ, Bootsma H, Spijkervet FK, Kroese FG, Vissink A. The microbiome-systemic diseases connection. Oral Dis. 2016;22(8):719-34.

\section{Publisher's Note}

Springer Nature remains neutral with regard to jurisdictional claims in published maps and institutional affiliations 